\title{
Satellite winds as a tool for offshore wind resource assessment: The Great Lakes Wind Atlas
}

\author{
Fri Jul 10 00:03:29 2015
}

, Paula Doubrawamycorrespondingauthor [mycorrespondingauthor]Corresponding author: 245 Upson Hall, 124 Hoy Rd., Ithaca NY 14850. Tel: +1 8123223182 pd343@ cornell.edu

, Rebecca J. Barthelmie rb737@ cornell.edu

, Sara C. Pryor sp2279@cornell.edu

, Charlotte B. Hasager cbha@dtu.dk

, Merete Badger mebc@dtu.dk

, Ioanna Karagali ioka@dtu.dk

Sibley School of Mechanical and Aerospace Engineering, Cornell University, Upson Hall, Ithaca NY 14850 NY 14850

Department of Earth and Atmospheric Sciences, Cornell University, Bradfield Hall, Ithaca

DTU Wind Energy, Risø Campus, Technical University of Denmark, Frederiksborgvej 399, 4000 Roskilde, Denmark

This work presents a new observational wind atlas for the Great Lakes, and proposes a methodology to combine in situ and satellite wind observations for offshore wind resource assessment.

Efficient wind energy projects rely on accurate wind resource estimates, which are complex to obtain offshore due to the temporal and spatial sparseness of observations, and the potential for temporal data gaps introduced by the formation of ice during winter months, especially in freshwater lakes.

For this study, in situ observations from 70 coastal stations and 20 buoys provide diurnal, seasonal, and interannual wind variability information, with time series that range from 3 to 11 years in duration. Remotely-sensed equivalent neutral winds provide spatial information on the wind climate. NASA QuikSCAT winds are temporally consistent at a $25 \mathrm{~km}$ resolution. ESA Synthetic Aperture Radar winds are temporally sparse but at a resolution of $500 \mathrm{~m}$.

As an initial step, each data set is processed independently to create a map of $90 \mathrm{~m}$ wind speeds.

Buoy data are corrected for ice season gaps using ratios of the mean and mean cubed of the Weibull distribution, and reference temporally-complete time series from the North American Regional Reanalysis. Generalized wind climates are obtained for each buoy and coastal site with the wind model WAsP, and combined into a single wind speed estimate for the Great Lakes region.

The method of classes is used to account for the temporal sparseness in the SAR data set and combine all scenes into one wind speed map.

QuikSCAT winds undergo a seasonal correction due to lack of data during the cold season that is based on its ratio relative to buoy time series. 
All processing steps reduce the biases of the individual maps relative to the buoy observed wind climates.

The remote sensing maps are combined by using QuikSCAT to scale the magnitude of the SAR map.

Finally, the in situ predicted wind speeds are incorporated.

The mean spatial bias of the final map when compared to buoy time series is $0.1 \mathrm{~ms}^{-1}$ and the RMSE $0.3 \mathrm{~ms}^{-1}$, which represents an uncertainty reduction of $50 \%$ relative to using only SAR, and of $40 \%$ to using only SAR and QuikSCAT without in situ observations.

\section{Wind Climate}

Offshore wind SAR QuikSCAT Great Lakes Resource Assessment Wind Atlas

\section{Introduction}

The Great Lakes extend over $240,000 \mathrm{~km}^{2}$, accounting for $21 \%$ of the total surface freshwater of the planet and $84 \%$ of North American resources [7], with maximum depths varying from $19 \mathrm{~m}$ in Lake Erie to $406 \mathrm{~m}$ in Lake Superior (fig:sites). The population in the area that spans across 8 U.S. states and 2 Canadian provinces is over 33 million [4]. Because of their large expanse, highly available wind resource, and the proximity to large electricity demand centers, the Great Lakes have been considered a potential location for wind energy development for many decades (e.g., [14]). However, over water the wind climate and thus the wind resource is difficult to accurately quantify. The formation of surface ice during winter months [35] precludes retrieval of wind speeds from satellites and necessitates removal of buoys. Additionally, offshore observations are spatially sparse, and availability of satellite imagery for wind retrieval is limited relative to the data requirements necessary to derive a stable estimate of the wind resource [2]. The first attempt to estimate the wind resource in the Great Lakes region was conducted in 1981 [25]. It was based on sparse land-based observations and therefore only estimated the resource over land and along the coast. In 1986, the Canadian government compiled a climatological wind atlas of the region [30]. It was based on data visually recorded on ships, along with meteorological records from the United States and Canada. Later, Environment Canada produced a Canadian Wind Energy Atlas that was based on statistical-dynamical downscaling of mesoscale model simulation outputs and included most of the Great Lakes [8]. More recently, two additional model-based efforts were undertaken. [17] analyzed the wind resource at $80 \mathrm{~m}$ and the wind variability of the Great Lakes based on North American Regional Reanalysis (NARR) data. AWS Truepower and the National Renewable Energy Laboratory [32] produced a wind resource map of the United States that includes the U.S. section of the Great Lakes and was derived from wind flow model simulations and corrected based on observations. However, detailed descriptions of the methodology and data used in that effort are not publicly available.

The objective of this study is to explore the strengths of different observational data sets for winds over the Great Lakes, and to produce an observationally-based wind atlas while providing detailed documentation regarding the methods used. In situ observations from coastal stations and buoys are used, as well as satellite winds from the European Space Agency (ESA) Envisat Synthetic Aperture Radar (SAR) and from the National Aeronautics and Space Administration (NASA) QuikSCAT scatterometer. 
So far, offshore wind resource studies based on SAR and QuikSCAT have mostly focused on the European Seas (e.g., [1], [9], [15], [10]) and very little attention has been given to North American offshore waters, where studies have used short time series and focused on data validation (e.g., [36]; [26]) rather than developing methods for accurate wind resource estimation. In this work, we present a method to combine wind measurements from satellite platforms, coastal stations, and buoys that bridges the spatial and temporal limitations inherent in each data set and seeks to characterize the long-term variability of the wind resource. The methods herein presented could be successfully applied to other offshore regions to produce a low-bias wind resource assessment. sec:data_meth describes the data and the methods applied to each data set, and presents the results obtained when using a single data set to obtain a prediction of the Great Lakes mean wind climate. The final results are presented in sec:atlas, followed by a summary and final discussion in sec:summary.

\section{Data and Methods}

In order to estimate the wind resource of the Great Lakes, this study incorporates both remote sensing and in situ wind observations. This section provides a thorough description of these different measurements, and of the methods applied to each one in order to obtain the Great Lakes observational wind atlas. Although the observations are generally representative of lower heights, this work focuses at the height of $90 \mathrm{~m}$ to reflect typical turbine hub-height and to facilitate comparison with an existing wind resource map for this region [32]. The vertical extrapolation is performed differently for the remote sensing and the in situ data and is described throughout this section. The wind atlas is a large-scale, long-term statistical description of the wind climate, and therefore the complex dynamics of local and diurnal effects such as low-level jets are beyond the scope of the methodology employed. Each available data set has both advantages and disadvantages and different characteristics and error statistics. For example, the in situ measurements are disjunct time series of temporal averages taken at a point, while the satellite-based remote sensing values are pseudo instantaneous, spatial averages with varying disjunct sampling frequency. The method of data integration employed herein seeks to capitalize on the strengths of each data set, and to address their respective weaknesses by applying data set-specific pre-processing and processing steps, which are summarized by the schematic in fig:flux.

\subsection{In Situ}

The in situ measurements used in this study come from 70 meteorological stations at coastal sites and from 20 buoys (fig:sites) and are obtained from 2002 to 2012. The data for U.S. sites were obtained from the National Data Buoy Center (http://www.ndbc.noaa.gov/) and depending on the location they were maintained by the Coastal-Marine Automated Network (C-MAN), the National Oceanic and Atmospheric Administration (NOAA) National Ocean Service (NOS), the National Weather Service (NWS), or the Great Lakes Environmental Research Laboratory (GLERL). The data for Canadian sites were obtained from the Ontario Climate Center (http://climate.weather.gc.ca/). All sites are equipped with propeller anemometers. Data are reported every 6 minutes to 1 hour, with sporadic periods of higher frequency. Because of the high frequency and long record, we assume that diurnal, seasonal, and interannual variability are captured in the mean wind climates derived from these data. The coastal stations have long-term records but represent coastal conditions. The buoys capture offshore conditions but are less numerous and unavailable during the cold season, when they are removed from the Lakes due to 
ice formation. Both provide measurements at relatively low heights, with anemometer heights ranging from 6.4 to $46.9 \mathrm{~m}$ for the coastal stations and from 3.2 to $5.0 \mathrm{~m}$ for the buoys.

\subsubsection{Quality Control}

Quality control was performed on data from coastal sites and buoys to reduce uncertainties and to prevent seasonal biases from affecting the wind atlas calculations. Inaccurate and unrealistic values were identified using the following criteria (qc0qc3) and removed from the time series.

$$
\begin{aligned}
& \text { pluralequation]qcs } \\
& \text { equation } 0|\vec{u}|<0.4 m s^{-1} \\
& |\vec{u}|>75 m s^{-1} \\
& \left|\vec{u}_{i}\right|>\left|\vec{u}_{i-1}\right| * 1.5 \text { and }\left|\vec{u}_{i}\right|>\left|\vec{u}_{i+1}\right| * 1.5 \mathrm{if}\left|\vec{u}_{i}\right|>15 \mathrm{~ms}^{-1} \\
& 0>\theta>360
\end{aligned}
$$

The anemometer response can be slow near its cut-in value since it needs to overcome mechanical friction and inertia to start spinning. As a consequence, the observations in the first bin of the observational histogram $\left(0-1 \mathrm{~ms}^{-1}\right)$ include erroneous values as well as wind speeds below $1 \mathrm{~ms}^{-1}$. To prevent this excessive number of calm recordings from skewing the Weibull distribution fit, qc0 is applied to remove a portion of these erroneous values, while still allowing a sufficient number of low but legitimate wind speed values to remain for the proper fitting of the distribution. qc1 removes possibly erroneous high values [38] that are sometimes present in the original data due to formatting or recording issues. Instead of defining the maximum allowed variability as a fixed value, qc 2 was used to remove any isolated high entries by filtering out values that are more than $150 \%$ of both the previous and the following entries. This criterion was applied only to very high wind speeds $\left(u>15 \mathrm{~ms}^{-1}\right.$ at anemometer height) and filtered out a negligible portion of the data $(\sim 0.002 \%)$.

To avoid seasonal biases, each coastal site was conditioned to keep only sampled years of data for which each month had an availability $\geq 70 \%$ (e.g. for hourly observations in January the total possible is $24 * 31$ so a minimum of 521 entries was required). Moreover, only sites with at least three years of complete data were kept in the analysis, in order to minimize the impact of interannual variability biases on the wind climate. For the 11-year period considered, the annual mean wind speeds averaged across sites were $\sim 5.0 \mathrm{~ms}^{-1}$ for buoys and $\sim 4.8 \mathrm{~ms}^{-1}$ for coastal stations, with an interannual variability of $\pm 0.6 \mathrm{~ms}^{-1}$ and $\pm 0.5 \mathrm{~ms}^{-1}$ respectively. The number of years of data used for each site after quality control varies from 3 to 11 years (fig:sites). Note that fig:sites does not represent the number of years rejected during quality control, since very few sites were operational during the entire 11-year period. Each year has measurements from at least 3 sites (coastal or buoy) in each lake (fig:sitesyear). The lake with fewest sites is Lake Michigan from 2002 to 2005. In contrast, the most robust representation is for Lake Huron in 2011 and 2012, where 21 sites were available with complete data.

\subsubsection{Wind Climates}

To reconcile measurements taken at different heights (anemometer heights for the in situ measurements vary from $3.2 \mathrm{~m}$ to $46.9 \mathrm{~m}$ ) and in different local wind regimes and thus develop an integrated wind resource estimate at a standard height (here of $90 \mathrm{~m}$ ), the in situ time series of data from each site were used to develop generalizable wind climates (fig:flux) using the Wind Atlas Analysis and Application Program (WAsP) [20]. WAsP is the most widely used model for wind resource assessment. It uses roughness, topography and internal boundary layer models, and the geostrophic drag law to extrapolate the observations from a mast (at anemometer height) to other points in space (often to hub height). The mean wind climates are statistical summaries of wind 
conditions at a given site and are produced as follows: the time series of wind speeds and directions are used to generate 30 wind direction sector-specific histograms of the wind speeds (i.e., the observed wind climate in fig:flux) from which the Weibull scale and shape parameters (A and $\mathrm{k}$, respectively) are derived. Then these wind climates in each sector are generalized by removing the local effects of orography and roughness to obtain a value for the geostrophic wind that is independent of the surface conditions and assumed to be homogeneous within a given area [34]. This value can then be used to obtain the wind climate over an area of approximately a $50 \mathrm{~km}$ radius from the station, by reincorporating the orography and roughness characteristics of the target points. In this application the orography was described using NASA's Shuttle Radar Topography Mission data at a resolution of 30 arc-seconds (approximately $0.9 \mathrm{~km}$ in latitude and 0.6 to $0.7 \mathrm{~km}$ in longitude for the Great Lakes geographical location), the over-water roughness length was assumed to be $0.0002 \mathrm{~m}$, and the roughness length over land was assumed to be $0.1 \mathrm{~m}$. Obstacles were not taken into account since the focus of this work is offshore resource assessment. The standard WAsP parameters were used, which include a slightly unstable atmosphere offshore, with a heat flux of $15 \mathrm{Wm}^{-2}$. Using these assumptions, generalizable wind climates (i.e., the statistical wind climate in fig:flux) were derived for heights $(z)$ of 10, 25, 50, 90 and $150 \mathrm{~m}$ and roughness lengths $\left(z_{0}\right)$ of $0.0002,0.03,0.1$, and $0.4 \mathrm{~m}$ for all buoys and coastal stations following the well established wind atlas methodology [34].

\subsubsection{Seasonal Correction}

Because the Great Lakes system is a high latitude freshwater system, it is subject to extensive ice cover [23], [35]. This poses a challenge both for prospective wind deployment (though use of ice-cones can greatly reduce foundation loading from ice floes [27]) and for accurate quantification of the wind resource, because during the ice formation months the buoys are removed from the Lakes. During the 11-year period considered, the average length of cold-season data gaps varied from 3.1 to 5.5 months across the buoy locations, with a spatial average of 4.1 months of missing data per cold season per site. Thus a correction was applied to each buoy generalized wind climate to correct for the absence of cold-season data. A reference data set was used in this procedure, namely the National Center for Environmental Prediction (NCEP) North American Regional Reanalysis (NARR) [18]. These data are for a nominal height of $10 \mathrm{~m}$, and are available at 3-hourly intervals at a spatial resolution of $32 \mathrm{~km}$. The method applied to correct for the missing buoy observations is based on the measure-correlate-predict method of ratios [5]. For each standard roughness and height, the mean and the mean cubed of the Weibull distribution were calculated according to eq:moms [34], where $m^{n}$ represents the first moment (i.e., the mean) to the $n^{t h}$ power $\left[m s^{-1}\right]^{n}, A$ the scale parameter $\left[m s^{-1}\right]$ and $k$ the shape parameter of the Weibull distribution, and $\Gamma$ the gamma function.

$$
m^{n}=A^{n} \Gamma\left(1+\frac{n}{k}\right)
$$

Concurrently, the mean and mean cubed were calculated for the reference time series considering two scenarios: a complete data record that includes the cold season, and a shorter record that includes only the time stamps that coincide with the buoy availability. For those coinciding time stamps, a ratio of the moments was obtained. This ratio and the moments for the complete-record reference series were then used to obtain corrected buoy moments, as given by eq:mcp where the subscript $o$ represents the original buoy series and $r$ the reference series.

$$
m_{o, \text { corrected }}^{n}=\frac{m_{o, \text { short }}^{n}}{m_{r, \text { short }}^{n}} m_{r, \text { complete }}^{n}
$$

Once the moments have been corrected, eq:moms can be used again to recalculate the Weibull 
parameters $A$ and $k$, which now describe the corrected generalized wind climate.

\subsubsection{Validation of Seasonal Correction}

The validity of this seasonal correction was tested on data from the coastal stations, for which complete time series are available. Thus, the method applied in subsec:seasonal_corr_sites is evaluated here by deriving time series for the coastal stations that mimic the fractured buoy data sets and by comparing them against the complete time series. The all-sector percent errors between the generalizable wind climate derived from the original complete time series and the "corrected" complete series are shown in fig:box_errors. These errors were calculated for the height of $90 \mathrm{~m}$ and four roughness classes for the mean and for wind power density $P\left[\mathrm{Wm}^{-2}\right]$, which is given by eq:power_density, where the air density $\rho$ was taken to be $1.225 \mathrm{kgm}^{-3}$. Errors were calculated as $\left(x_{\text {true }}-x_{\text {estimate }}\right) / x_{\text {true }}$.

$$
P=\frac{1}{2} \rho A^{3} \Gamma\left(1+\frac{3}{k}\right)
$$

The approach is generally robust. For the first moment (i.e., the mean), all errors were within $10 \%$. When averaged across roughness classes, the mean error was $-0.8 \%$, the median $-1.3 \%$, and the standard deviation $4.1 \%$. For the power density, the cube relation of the scale factor $\left(A^{3}\right.$ in eq:power_density) amplifies uncertainties and the errors are higher. They were within $25 \%$, with a roughness-averaged mean of $-1.8 \%$, a median of $-3.3 \%$, and a standard deviation of $-10.6 \%$. As indicated, the mean error is generally negative which indicates that the moment-ratio correction method slightly under-corrects for the sampling bias introduced by the removal of buoys due to the presence of ice on the Lakes.

\subsubsection{Seasonal Correction Results}

The differences between the predicted wind resource at $90 \mathrm{~m}$ before and after the buoy correction are shown in tab:diff_before_after_corr for wind speed $u$ and wind power density $P$ as given by eq:power_density. They were highest for Lake Superior, where the predicted $P$ was $\sim 34 \%$ higher after the correction for missing data due to ice cover, and lowest for Lake Erie, where it was $\sim 14 \%$ higher. The predicted resource at $90 \mathrm{~m}$ offshore was also calculated using the artificially incomplete May-Oct coastal time series and their complete Jan-Dec counterparts, for the 70 coastal stations. The results are shown in bold in tab:diff_before_after_corr. Consistent with prior modeling analysis that has indicated higher wind speeds during the cold season and the importance of ice cover to determining wind regimes over lakes [17], application of the correction increases the wind resource and exhibits variation across the Lakes. In terms of power density, the highest difference for the coastal stations is seen for Lake Erie $(\triangle P \sim 57 \%)$ and the lowest for Lake Superior $(\triangle P \sim 28 \%)$.

Table 1: Difference $\left(x_{\text {after }}-x_{\text {before }}\right)$ in wind resource at $90 \mathrm{~m}$ as predicted by WAsP (wind speed $u$ and power density $P$ ) before and after the seasonal correction was applied to data from the buoys and to the artificially incomplete coastal sites (boldface), calculated at each site and

spatially averaged over each Lake (number of sites per Lake is given).

\begin{tabular}{|c|c|c|c|c|c|}
\hline $\mathrm{m}] \quad[0.14 \mathrm{e}$ & $\Delta u\left[m s^{-1}\right]$ & $\Delta u[\%]$ & $\Delta P\left[W m^{-2}\right]$ & $\Delta P[\%]$ & $\begin{array}{l}\text { Number } \\
\text { Sites }\end{array}$ \\
\hline $\begin{array}{r}0.05 \mathrm{e} \\
\text { m] Superior }\end{array}$ & 0.8 & $10.2 \quad 11.8$, & $\mathbf{7 4} 125$, & $28.1 \quad 33.8$, & $4, \mathbf{1 4}$ \\
\hline an Michig & 0.7 & 10.2 , & 105 & 26.1, & 2,19 \\
\hline
\end{tabular}




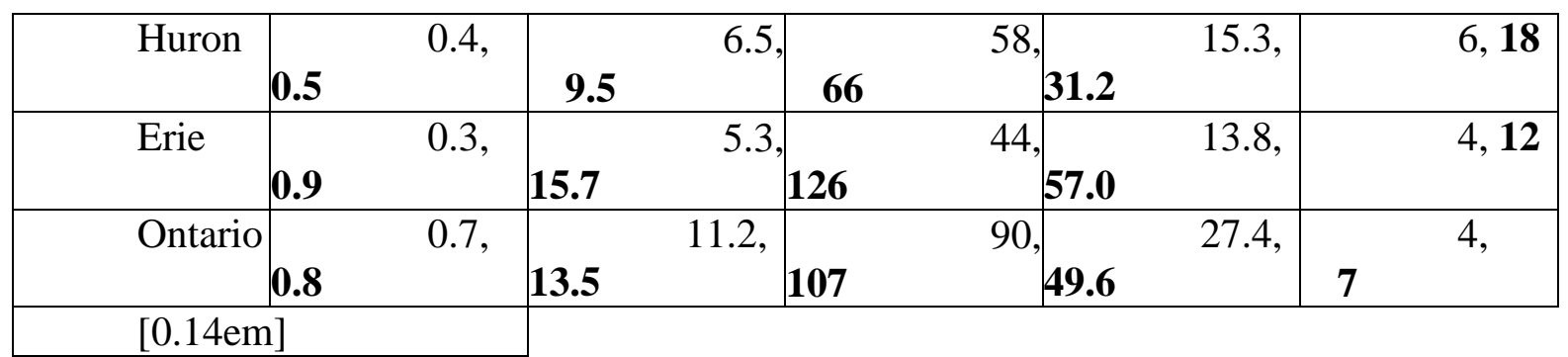

\subsubsection{Predicted Wind Speeds}

Once the correction was applied, the generalized wind climates for each buoy and coastal station were used in WAsP to produce 90 wind resource maps centered at each of the 90 sites. For the coastal stations, the resource maps extended over a radius of $25 \mathrm{~km}$. Because the buoys are offshore where winds are likely to be more homogeneous, resource maps for the buoys extended out to $50 \mathrm{~km}$ from the center. The resource maps were discretized with $1 \mathrm{~km}$ resolution. The 90 individual maps were then merged using bilinear interpolation as the resampling method, considering a weighted average of the four closest pixel centers. Once combined, the map was gridded using a kriging method [24] to generate a homogenized wind resource at $90 \mathrm{~m}$ (fig:resource_sites). The spatial heterogeneity of the resource map (localized maxima and minima) are the result of the data sparseness and the interpolation, and re-emphasizes the value of integration of over-lake remote sensing data. Since each site produced an individual resource map ( $25 \mathrm{~km} \times 25 \mathrm{~km}$ for coastal stations and $50 \mathrm{~km} \times 50 \mathrm{~km}$ for buoys), the proximity of sites seen at some locations led to the overlapping of individual resource maps. Upon interpolation and gridding, the overlapping areas introduce some uncertainty in the wind resource at the buoy locations, as is seen by the mean bias values in fig:resource_sites for Lake Ontario and Lake Saint Clair. Hereafter, "bias" refers to a measure of the uncertainty in the method determined by the difference in an observed and interpolated value. The bias is given by eq:error, where $u_{90_{M}}$ is the mean wind speed at $90 \mathrm{~m}$ as predicted by the method being presented, and $u_{90_{W}}$ is the mean wind speed at $90 \mathrm{~m}$ as predicted by WAsP from ice season-corrected buoy data. Root-mean-square errors (RMSE) are calculated according to eq:rmse where $N_{\text {buoys }}$ is the number of buoy sites being used in the error calculation.

$$
\begin{aligned}
& \text { bias }=u_{90_{M}}-u_{90_{W}} \\
& \text { RMSE }=\sqrt{\frac{\sum_{\text {buoys }}\left(u_{90_{M}}-u_{90_{W}}\right)^{2}}{N_{\text {buoys }}}}
\end{aligned}
$$

The bias values ranged from -0.4 to $0.8 \mathrm{~ms}^{-1}$ (fig:resource_sites), with a mean bias of $\sim 0.0 \mathrm{~ms}^{-1}$ when averaged over all buoy locations, and a RMSE of $\sim 0.2 \mathrm{~ms}^{-1}$.

\subsection{SAR}

Because of its high resolution, SAR provides detailed information on the spatial variability of the wind offshore and near the coast. For that reason, it has been considered as a valuable tool for offshore wind resource assessment for over a decade (e.g. [2], [11]). Several methods have been proposed to obtain accurate offshore wind resource estimates from SAR scenes that include information on the spatial and temporal variability of the local wind climate. [28] found that a minimum of 60 serially independent satellite scenes are necessary to obtain a 
statistical representation of the mean wind speed with an uncertainty below $\pm 10 \%$ for a confidence level of $90 \%$. [1] showed that selecting SAR scenes according to wind classes that are representative of the local wind climate resulted in an improvement over randomly sampling the available scenes. Despite being temporally limited and sometimes spatially sparse, SAR data provide excellent spatial coverage and relatively high accuracy in some regions [2]. Because of their high resolution they are also available close to the coast [13], and add detail to the representation of spatial variability offshore [10]. Synthetic Aperture Radar (SAR) data used herein were obtained from the Envisat mission by the European Spage Agency (ESA). Level 1 data products acquired in Wide Swath Mode (WSM) with the swath width of $400 \mathrm{~km}$ and a spatial resolution of $150 \mathrm{~m}$ are used. These are available for a long period (2002 to 2012) and at a low frequency (one to fifteen times per month in this region). Wind speed maps are retrieved from the SAR scenes using a Geophysical Model Function (GMF), which describes the empirical relationship between the wind speed, the radar backscatter from the water surface, and the radar viewing geometry (see [6] for an overview of SAR wind retrieval). Here the GMF called CMOD5.n [12] is applied with input wind directions from the U.S. Navy's Operational Global Atmospheric Prediction System Model (NOGAPS).

\subsubsection{Quality Control}

During the period from 2002-2012, a total of 764 SAR scenes are available from the ESA archive (https://earth.esa.int/web/guest/missions/esa-operational-eo-missions/ers/instruments/sar) for the Great Lakes region (fig:nscenes_space). The presence of ice can lead the algorithm to return unrealistic high wind speed values. Therefore, areas covered by sea ice are masked out using the IMS Daily Northern Hemisphere Snow and Ice Analysis at $4 \mathrm{~km}$ resolution [21]. The output maps give the 10-m Equivalent Neutral Wind (ENW) in 500-m grid cells. Cells of the original SAR scenes were averaged to this size in order to reduce effects of random noise, long-period waves, and hard targets in the SAR data. Values smaller than $2 \mathrm{~ms}^{-1}$ or greater than $25 \mathrm{~ms}^{-1}$ at $10 \mathrm{~m}$ height were removed because they were expected to have a high level of uncertainty. No attempts were made to mask out rain effects as the rain sensitivity of C-band SAR is very limited. Inaccuracies due to these limitations in sensor recording ranges are expected to be smoothed out by the integration with the other data sets (sec:atlas).

\subsubsection{Wind Class Method}

Because of the temporal sparseness of the SAR observations, a statistical analysis of the wind resource, as was conducted for the in situ data, is not viable. Thus an alternative based on wind classes [1] is used here. This method integrates all available satellite scenes by assigning each pixel of each swath to a specific pre-defined wind class based on its wind speed and direction and then by combining the classes using a weighted average. The classes are representative of the regional wind climate (i.e., representative of a spatial distribution of wind speed for a given wind speed and direction) and the weights describe the frequency of occurrence for that particular wind class. Classes and their respective weights are obtained from a separate data set which includes information on diurnal, seasonal and interannual variability of the wind resource. In this study, the classes and weights were obtained separately for each Lake using observational data from a number of coastal stations. The choice of sites (fig:nscenes_space) was based on their length of record and their position, in order to ensure a representation of the wind climate at several geographical locations around each of the Lakes. For each Lake, the data were divided into 12 directional sectors and within each sector, into 4 wind speed classes (fig:classrose). The frequency of occurrence of measurements within each of the 48 classes was obtained and later used as weights to combine the several SAR scenes. Each pixel in each SAR scene was assigned to one of 
the classes according to its wind speed and direction. The arithmetic mean was used to obtain the pixel wind speed if more than one pixel was assigned to the same class and the same geographical location. The wind class method combines all available wind speed data from the SAR images into 48 maps (one for each class) for each Lake. This methodology seeks to overcome the spatiotemporal sparseness of the SAR scenes. Two examples of classes are shown for Lake Erie in fig:ex_classes, where (a) represents $\theta=0 \pm 15$ and $5 \leq|\vec{u}|<10 \mathrm{~ms}^{-1}$ with a weight of $2.06 \%$ (since $2.06 \%$ of all data for Lake Erie fall into this category), and (b) represents $\theta=180 \pm 15$ and $4 \leq|\vec{u}|<7 \mathrm{~ms}^{-1}$ with a weight of $4.73 \%$. This means that the weights for the other 46 classes for the same lake add up to $93.21 \%$. The white patches in fig:ex_classes indicate that none of the 764 SAR scenes had observations within that class for that location.

\subsubsection{Predicted Wind Speed}

A weighted average of the 48 individual maps (one for each wind class) yields a single resource map from the SAR satellite winds that accounts for the lack of seasonal and interannual representativeness inherent in the temporally sparse data. To allow integration with the in situ observations, the final winds were extrapolated from $10 \mathrm{~m}$ to the height of $90 \mathrm{~m}$ using the neutral logarithmic profile given by eq:10_to_90, where $z_{0}=0.0002 \mathrm{~m}$ (fig:resource_sar).

$$
u_{90}=u_{10}\left[\frac{\ln \left(90 / z_{0}\right)}{\ln \left(10 / z_{0}\right)}\right]
$$

This vertical extrapolation was applied to the remote sensing ENW. [10] found the mean difference between SAR ENW and mast stability-dependent winds (SDW) to be $\sim 0.07 \mathrm{~ms}^{-1}$ at $10 \mathrm{~m}$ height for offshore Denmark, with the neutral winds being higher. This difference can be used to approximate the uncertainty due to vertical extrapolation assuming a near-neutral stability. In order to obtain such an estimate for the Great Lakes, we used the air temperature, water temperature, and wind speed data from the 20 buoys to estimate the friction velocity $u_{*}$ and roughness length $z_{0}$ using the bulk flux algorithm of [3]. These values were then used to obtain time series of neutral winds for the buoys. Averaging over the entire time record and in space, we found the ENW to be higher than the SDW by $\sim 0.16 \mathrm{~ms}^{-1}$, with differences ranging from $\sim 0.01 \mathrm{~ms}^{-1}$ to $\sim 0.3 \mathrm{~ms}^{-1}$ as a function of the measured SDW. This value indicates an uncertainty of on the order of $10^{-1} \mathrm{~ms}^{-1}$ in the mean wind map obtained from SAR.

In contrast to the map from in situ observations, the SAR mean wind map is spatially smooth due to the ample spatial coverage of the SAR scenes. Point biases were calculated by using the SAR map pixel closest to the buoy coordinate locations. The bias calculated against the predicted mean wind speed at the buoy locations (fig:resource_sar) has a spatial maximum of $1.4 m s^{-1}$, a mean of $\sim-0.1 m s^{-1}$ and a RMSE of $\sim 0.6 m s^{-1}$. At the majority of the sites the mean wind speed derived from SAR exhibits a positive bias relative to the buoy-derived estimate (fig:resource_sar).

\subsection{QuikSCAT}

The term QuikSCAT refers to NASA's SeaWinds Quick Ku-Band Scatterometer. The primary objective of the mission upon launching in 1999 was to measure near-surface ocean winds. Wind information used herein are the daily gridded maps from Remote Sensing Systems (RSS) QuikSCAT v4 ENW, which are retrieved based on the measured surface roughness using the Geophysical Model Function Ku-2011 [29]. The mission lasted until 2009 and its product is available at a much higher frequency (twice daily) than SAR, but at a much lower resolution $(\sim 25$ $\mathrm{km}$ ). Thus, wind fields are not directly available close to the coast, where specialized retrieval algorithms are necessary to resolve the wind vectors ([33], [22]). Quality control included rain-flagging and the use of a threshold in data availability, i.e. only grid cells with more than 720 
observations were used (approximately the equivalent of 2 observations per day for a one year period). Stronger backscatter signal due to structures offshore could lead to a partial increase in wind speed [16]. However, no backscatter signal information was available from the used product and no screening for traffic could be performed. Data availability from QuikSCAT (fig:nscenes_space_qs) is consistently higher than from SAR but is limited to Lakes Superior, Michigan, Huron and Georgian Bay. The high data density from the scatterometer means application of the wind class method as applied to the SAR data is not necessary.

\subsubsection{Seasonal Correction}

No wind information can be derived from radar backscatter when there is ice formation, so there is a need to correct for the absence of scatterometer data during the ice season. This correction was done using observational data from the sites that spatially overlap with the QuikSCAT coverage of the Lakes. This translates to 9, 6, and 7 sites for Lakes Superior, Michigan and Huron respectively. For each site, two temporal averages of the wind speeds were calculated: for January-December and for May-December. A ratio $r$ of these means was obtained and averaged spatially for each Lake, and Lake Huron was further divided into main Lake Huron and its northern section, known as Georgian Bay. These mean $r$ values (see tab:qs_correction) were then used as a scale factor to correct the mean wind speeds obtained from the QuikSCAT scenes. As for SAR, the point biases for the raw and the corrected QuikSCAT estimates were calculated by using the map pixel closest to the buoy coordinate locations. The correction had the largest impact on Georgian Bay, where the bias (relative to the buoy observed wind climates) was the largest and went from $\sim 0.95 \mathrm{~ms}^{-1}$ to $\sim 0.60 \mathrm{~ms}^{-1}$ after application of the seasonal correction. A slight positive (negative) difference was seen for Lake Superior (Michigan), and no difference for Lake Huron. At Georgian Bay, the number of QuikSCAT observations is significantly lower than for Lakes Superior, Michigan and Huron. Thus, the wind speed correction for missing observations due to ice cover appears to be most useful in regions where the number of satellite observations is lower.

Table 2: Temporal and spatial mean winds at 90m for the periods Jan-Dec and May-Dec based on in situ measurements from sites overlapping with the QSCAT coverage, and their ratios. The mean bias of the QuikSCAT resource map is based on buoy time series (eq:error), and calculated before and after the seasonal correction was applied.

\begin{tabular}{|c|c|c|c|c|c|}
\hline$[0.14 \mathrm{e}$ & $\begin{array}{l}\text { Mean } \\
\text { Wind Jan-Dec } \\
{\left[\mathrm{ms}^{-1}\right]}\end{array}$ & $\begin{array}{r}\text { Mean } \\
\text { Wind May-Dec } r \\
{\left[\mathrm{~ms}^{-1}\right]}\end{array}$ & Ratio & $\begin{array}{r}\text { Mean } \\
\text { Bias Original }\end{array}$ & \\
\hline$\left[\mathrm{ms}^{-1}\right]$ & $\begin{array}{l}\text { Mean } \\
\text { Bias Corrected } \\
{\left[\mathrm{ms}^{-1}\right]}\end{array}$ & & & & \\
\hline \begin{tabular}{|c|}
{$[0.05 \mathrm{e}$} \\
$\mathrm{m}]$ Superior
\end{tabular} & 5.9 & 5.8 & 1.02 & -0.3 & -0.2 \\
\hline \begin{tabular}{|ll} 
an & Michig \\
\end{tabular} & 5.3 & 5.2 & 1.03 & -0.1 & +0.2 \\
\hline Huron & 5.3 & 5.3 & 1.01 & -0.2 & -0.2 \\
\hline \begin{tabular}{|l} 
Georgi \\
an Bay
\end{tabular} & 5.1 & 5.4 & 0.95 & +1.0 & +0.6 \\
\hline
\end{tabular}




\subsubsection{Predicted Wind Speed}

Similarly to SAR, the QuikSCAT wind speeds were logarithmically extrapolated to $90 \mathrm{~m}$ according to eq:10_to_90. Since these are ENW, the same uncertainty estimate given in subsec:sar_predicted_wspd applies here. The resource map obtained from QuikSCAT winds with time averaging, seasonal correction for the lack of data during the cold season, and extrapolation to $90 \mathrm{~m}$ is shown in fig:resource_qs. The bias values range from -0.3 to $1.6 \mathrm{~ms}^{-1}$ (fig:resource_qs). The mean bias is $\sim 0.2 \mathrm{~ms}^{-1}$, and the RMSE $\sim 0.6 \mathrm{~ms}^{-1}$. In contrast to SAR the positive biases at individual sites are generally of larger magnitude than the negative biases, but the mean bias (averaged across all sites) is of similar magnitude (i.e. $-0.1 \mathrm{~ms}^{-1}$ for SAR versus $0.2 \mathrm{~ms}^{-1}$ for QuikSCAT).

\section{Integrated Wind Resource}

\subsection{Integration of Remote Sensing Predictions}

The individual mean wind speed maps were regridded into a rectilinear grid of 900 points in latitude by 1800 points in longitude, from $41.0 \mathrm{~N}$ to $50.0 \mathrm{~N}$ and $93.0 \mathrm{~W}$ to $75.0 \mathrm{~W}$. The SAR and QuikSCAT maps were regridded using bilinear interpolation, and the in situ map using a natural neighbor interpolation. These maps were then combined to generate a single integrated wind resource estimate.

The first step was to combine the remote sensing results. The radar and scatterometer winds are obtained with different geophysical model functions and therefore a discrepancy is to be expected between the two data sets. This discrepancy is higher closer to the coast and at low wind speeds [37]. [19] found that using QuikSCAT wind directions to initialize the SAR wind speed retrievals reduced the inversion biases, and suggested that combining these two data sources provides better wind estimates, especially in coastal areas. This combination also addresses the well recognized issue of a limited number of scenes and irregular coverage of the Great Lakes [22] . In this work, we propose a way of combining these two data sources after individual wind speed maps were already obtained, instead of during the SAR wind speed retrieval. Due to its high spatial resolution, SAR provides high fidelity information on the spatial distribution of wind speeds. The method of classes described in subsec:wind_class is applied to overcome the temporal sparseness of this data set and provide a more robust estimate of the mean wind. However, this method alone is not sufficient when few scenes are available, and results can be greatly improved when combined with a more reliable estimate of the mean wind. QuikSCAT offers a solution due to its frequent and consistent temporal record. Therefore, we used QuikSCAT to scale the results of the SAR map, thus leveraging the higher resolution of the SAR, while also benefiting from the high data density from scatterometers. First, the mean QuikSCAT coverage was calculated for each Lake as the mean number of pixels for each Lake, normalized against the maximum number of pixels for the entire data set (see fig:nscenes_space_qs). These values are shown in tab:qs_sar. Only lakes for which the mean coverage was greater than $70 \%$ were subject to the map-scaling procedure, which excluded Lakes Erie and Ontario and Georgian Bay. Then, a ratio was obtained between the QuikSCAT and the SAR mean wind speeds (spatially averaged over each Lake).

Assuming that the QuikSCAT winds are more representative of the wind resource in terms of magnitude, these ratios (tab:qs_sar) indicate that SAR underestimated the resource for Lakes Michigan and Huron and overestimated it for Lake Superior, which is in agreement with the biases calculated against the buoy mean wind climates and shown in fig:resource_sar. Since a single SAR scene does not cover the entire area of interest, the representativeness over each lake is not 
uniform. To account for that, we allowed the scaling ratios to be different for each lake. The map-scaling procedure decreased the SAR biases by a factor of five, going from a spatial mean of $\sim-0.5$ to $\sim-0.1 \mathrm{~ms}^{-1}$. This method provided better results in comparison to the buoy data than performing a simple average of the two resource maps (see tab:qs_sar), especially for Lakes Michigan and Huron where the largest SAR biases are seen.

Table 3: Mean bias for QuikSCAT, SAR and simple average of both; ratio used for map-scaling; mean percent QuikSCAT data availability; and biases from map-scaled SAR results. Biases are

calculated for each buoy site that overlaps with QuikSCAT spatial coverage, and spatially averaged over each lake. $u_{q s}$ and $u_{\text {sar }}$ represent mean wind speeds at $90 \mathrm{~m}$ from QuikSCAT and SAR respectively.

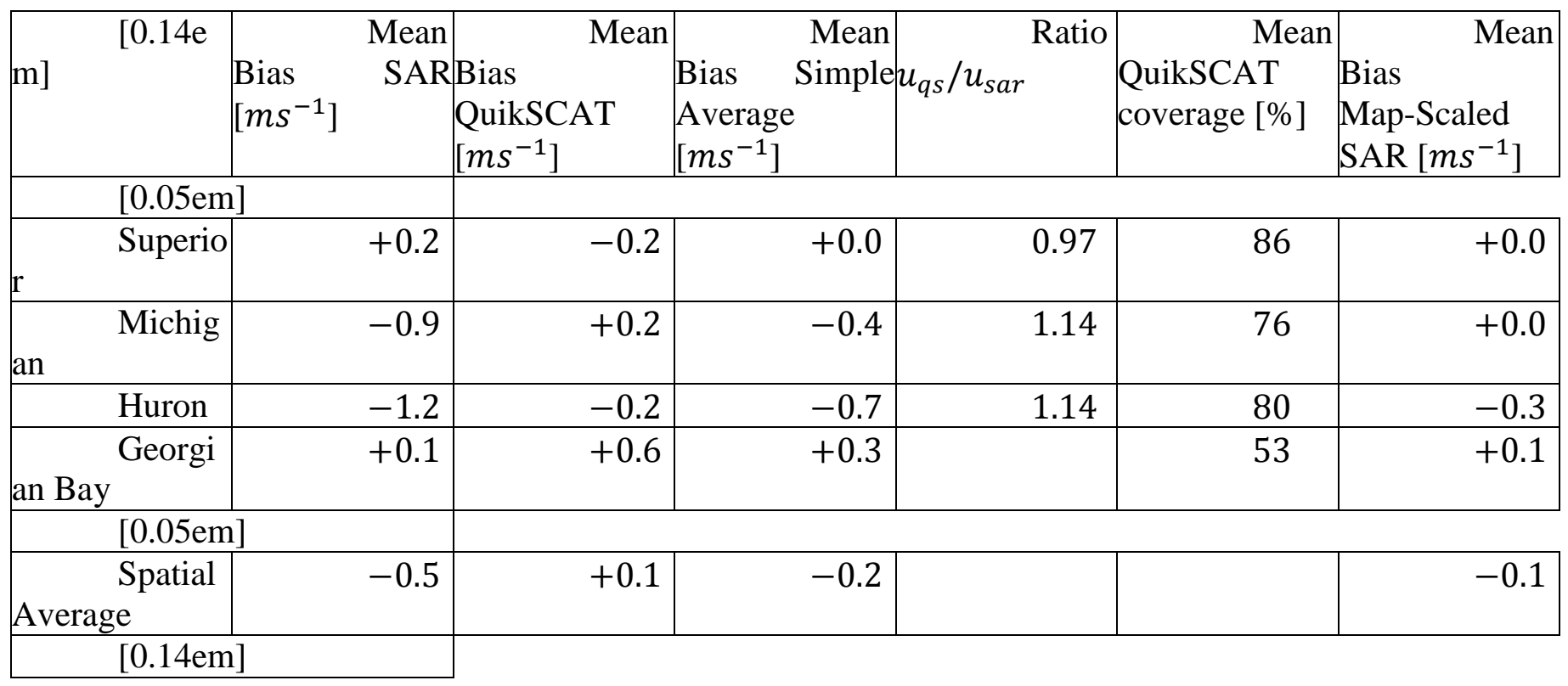

\subsection{Integration of In Situ and Remote Sensing Predictions}

The next step was to incorporate the wind speed map obtained from coastal stations and buoys into the remote-sensing wind speed map, to ensure that the predicted resource will also be scaled in coastal regions and in the smaller lakes, where a combination of QuikSCAT and SAR is not possible due to the QuikSCAT low resolution. This was done by performing an arithmetic average of the remote-sensing and the in-situ maps. Map-scaling was not applied in this step in order to retain some of the spatial information contained in the stations and buoys map. A 3-by-3 low-pass filter was applied twice to the final map in order to remove artificial high-frequency spatial variability that is introduced when combining the SAR satellite scenes with the wind class method. The final result is shown in a wind atlas format in fig:qs_sar_sites and the associated mean biases are given in tab:qs_sar_sites. Note that the "Map-Scaled SAR" biases are different from those in tab:qs_sar because here all sites are considered and not only those that spatially overlap with QuikSCAT coverage. The improvement relative to the individual wind speed maps was most obvious for Lakes Michigan and Huron, where the SAR biases were largest.

Table 4: Mean bias and RMSE (boldface) for SAR, Remote Sensing map (Map-Scaled SAR), and Remote Sensing and In Situ map (RSIS) at $90 \mathrm{~m}$. Biases and RMSEs are calculated for all buoy sites, and spatially averaged over each Lake. Differences between the model-based AWST 
and RSIS wind speed, calculated for the 9 United States buoy sites and spatially averaged over each lake.

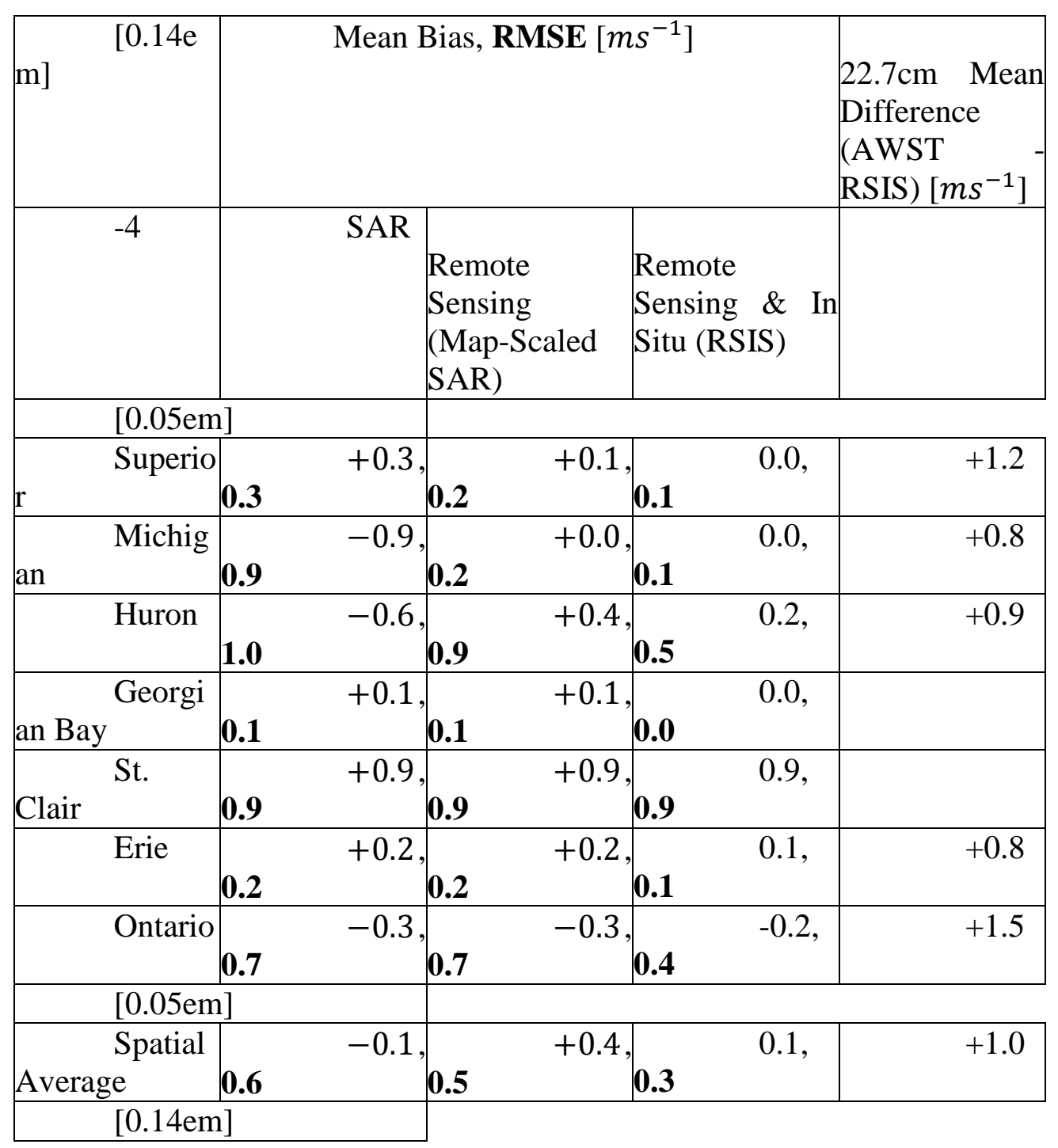

In order to illustrate the uncertainties in both observational and modeling studies, it is relevant to compare the Remote Sensing and In Situ (RSIS) estimate of the wind resource over the Great Lakes (fig:qs_sar_sites) with prior estimates, such as the one produced by AWS Truepower (AWST) from model data and calibrated with observations [32]. To do so, natural neighbor interpolation was used to regrid the AWST map. As shown in tab:qs_sar_sites, the differences are positive for all Lakes, indicating that the AWST technique predicted higher wind speeds than the method presented in this paper, by a spatial average of $\sim 1.0 \mathrm{~ms}^{-1}$. Detailed information about the methods employed to produce the AWST estimates is not publicly available. Thus, differences in the mean wind speeds at $90 \mathrm{~m}$ between these two analyses may reflect differences in (i) the time period considered (particularly given the high interannual variability driven by large-scale climate modes and ice cover in the Great Lakes [17], [31]) (ii) the data sets employed; (iii) the vertical extrapolation and stability corrections; (iv) the treatment of missing observations; and (v) the estimation of roughness length offshore. Future work will focus on quantifying the impact of the 
study assumptions and climate non-stationarity on Great Lakes wind resources.

\section{Discussion and Summary}

The objective of this work was to produce an observationally-derived wind atlas for the Great Lakes, taking advantage of different data sources, and to provide a blueprint for future observation-based offshore wind resource assessment efforts. Coastal stations provided long ( 3 to 11 years) and complete records that captured the diurnal, seasonal and interannual variability of the wind resource close to the coast. Buoys provided a long dataset ( $\sim 11$ years) and accurate representation of offshore conditions and were corrected for the lack of data during the ice season using a measure-correlate-predict method of ratios on the mean and mean cubed of the Weibull distribution. A long record of high-resolution North American Regional Reanalysis time series was used as a reference for the buoy correction. Satellite-derived winds contributed with the spatial coverage that in situ measurements cannot provide. QuikSCAT winds offered a spatially and temporally consistent long record (10 years) of wind measurements offshore at a low resolution, and away from the coast. On the other hand, SAR winds provided higher resolution including proximity to the coast, but with an inconsistent and irregular space and time coverage.

A wind resource map was produced individually for each satellite data set and for the in situ data. For the stations and buoys, small resource maps were generated with WAsP for each data point location and combined through bilinear interpolation and kriging. For QuikSCAT, an arithmetic average was used along with a correction for the lack of observations from January through April that was based on a linear relationship between the QuikSCAT time series and the buoys. This correction was especially valuable in regions where the satellite pixel density was lower. For SAR, the issue of disjunct sampling with varying time intervals and data scarceness was addressed with the wind class method. If the number of SAR scenes is limited, additionally to applying the method of classes the authors suggest scaling the resource based on a reliable wind speed estimate such as QuikSCAT winds. By using a robust wind speed estimate (QuikSCAT) to scale a robust wind speed spatial distribution estimate (SAR) we can obtain a resource map that contains dependable estimates of the magnitude of the wind speed and of its variation in space. This method addresses the issue of limited satellite coverage, and could be successfully employed in other regions beyond the Great Lakes. The scaled map was then averaged with the in situ map to obtain a final resource map that combined all of the observational data sets available for the Great Lakes region.

The uncertainty in the mean wind speeds at $90 \mathrm{~m}$ derived from the different data sources and in the combined spatial map are approximated by comparing the mean wind speed at $90 \mathrm{~m}$ with the value derived using observations at buoy sites. The atlas generated from all observational data sets presented the smallest biases, with a spatial mean of $0.1 \mathrm{~ms}^{-1}$ and a spatial RMSE of $0.3 \mathrm{~ms}^{-1}$. Some of the biases include uncertainties introduced during data processing (i.e., interpolation and gridding routines). Other sources of uncertainty were the assumptions that were made in order to manage the large volume of data, due to the long temporal record needed for a wind climate estimation and the large spatial coverage of the Great Lakes. The main assumptions were adopting a slightly unstable offshore profile during the generalized wind climate calculations for the in situ data in WAsP, using logarithmic vertical extrapolation, and keeping the satellite data as ENW. The first two assumptions are common in the wind atlas methodology [34]. For the latter, the uncertainty was estimated to be $\sim 0.16 \mathrm{~ms}^{-1}$ on average for the Great Lakes, as calculated from the 20 buoy time series.

This work demonstrated that the combination of several observational data sets can yield a 
robust wind atlas offshore, and that processing each data set separately with subsequent integration is extremely valuable since the biases of the final result are significantly smaller than those obtained when only one data set is used, or when the weaknesses in the data sets are not addressed. The methods presented in this work can be employed to address consistent gaps in time series, and to combine satellite and in situ wind data sets.

\section{Acknowledgments}

This work was funded by Department of Energy DE-EE0005379, National Science Foundation CBET-1464383, and National Renewable Energy Laboratory XFC-5-42084-01. The QuikSCAT product is made available by Remote Sensing Systems (RSS) and is sponsored by the NASA Ocean Vector Winds Science Team. SAR imagery is from European Space Agency.

\section{References}

\section{References}

[1] Merete Badger, Jake Badger, Morten Nielsen, Charlotte Bay Hasager, and Alfredo PeÃ \pm a. Wind Class Sampling of Satellite SAR Imagery for Offshore Wind Resource Mapping. Journal of Applied Meteorology and Climatology, 49(12):2474-2491, August 2010.

[2] R. J. Barthelmie and S. C. Pryor. Can Satellite Sampling of Offshore Wind Speeds Realistically Represent Wind Speed Distributions? Journal of Applied Meteorology, 42(1):83-94, January 2003.

[3] Anton C. M. Beljaars. The parametrization of surface fluxes in large-scale models under free convection. Quarterly Journal of the Royal Meteorological Society, 121(522):255-270, 1995.

[4] Lee Botts and Bruce Krushelnicki. The Great Lakes. An Environmental Atlas and Resource Book. United States Environmental Protection Agency \& Environment Canada, 1987.

[5] Jos Ã@ A. Carta, Sergio VelÃ $i z q u e z$, and Pedro Cabrera. A review of measure-correlate-predict (MCP) methods used to estimate long-term wind characteristics at a target site. Renewable and Sustainable Energy Reviews, 27:362-400, November 2013.

[6] Knut-Frode Dagestad, Jochen Horstmann, Alexis Mouche, William Perrie, Hui Shen, Biao Zhang, Xiaofeng Li, Frank Monaldo, William Pichel, Susanne Lehner, Merete Badger, Charlotte Bay Hasager, Birgitte Furevik, Ralph C. Foster, Silvia Falchetti, Michael J. Caruso, and Paris Vachon. Wind retrieval from synthetic aperture radar - an overview. In Proceedings of 
SEASAR 2012, ESA SP. European Space Agency, ESA, 2013.

[7] Environmental Protection Agency. Great Lakes Basic Information. July 2012. Accessed on 10/2014.

[8] Environment Canada. Canadian Wind Energy Atlas. 2003.

[9] Birgitte R. Furevik, Anna M. Sempreviva, Luigi Cavaleri, Jean-Michel Lef $\tilde{A} " v r e$, and Claudio Transerici. Eight years of wind measurements from scatterometer for wind resource mapping in the Mediterranean Sea. Wind Energy, 14(3):355-372, 2011.

[10] Charlotte B. Hasager, Alexis Mouche, Merete Badger, Ferhat Bing Ãgl, Ioanna Karagali, Tilly Driesenaar, Ad Stoffelen, Alfredo Pe $\tilde{A} \pm a$, and Nicolas Long $\tilde{A} \odot \mathrm{p} \tilde{A} \odot$. Offshore wind climatology based on synergetic use of Envisat ASAR, ASCAT and QuikSCAT. Remote Sensing of Environment, 156:247-263, January 2015.

[11] C. B. Hasager, E. Dellwik, M. Nielsen, and B. R. Furevik. Validation of ERS-2 SAR offshore wind-speed maps in the North Sea. International Journal of Remote Sensing, 25(19):3817-3841, October 2004.

[12] Hans Hersbach. Comparison of C-Band Scatterometer CMOD5.N Equivalent Neutral Winds with ECMWF. Journal of Atmospheric and Oceanic Technology, 27(4):721-736, April 2010.

[13] O.M. Johannessen and E. Bjorgo. Wind energy mapping of coastal zones by synthetic aperture radar (SAR) for siting potential windmill locations. 21(9):1781-1786, 2000.

[14] C. G. Justus and W. R. Hargraves. Wind energy statistics for large arrays of wind turbines, Great Lakes and Pacific Coast regions. Technical Report E-16-681, May 1977. Annual Progress Report, 1 May 1976 - 30 Apr. 1977, Georgia Inst. of Tech., Atlanta. School of Aerospace Engineering.

[15] Ioanna Karagali, Merete Badger, Andrea N. Hahmann, Alfredo PeÃ $\pm a$, Charlotte B. Hasager, and Anna Maria Sempreviva. Spatial and temporal variability of winds in the Northern European Seas. Renewable Energy, 57:200-210, September 2013. 
[16] Ioanna Karagali, Alfredo Pe $\tilde{A} \pm a$, Merete Badger, and Charlotte Bay Hasager. Wind characteristics in the North and Baltic Seas from the QuikSCAT satellite. Wind Energy, 17(1):123-140, January 2014.

[17] X. Li, S. Zhong, X. Bian, and W. E. Heilman. Climate and climate variability of the wind power resources in the Great Lakes region of the United States. Journal of Geophysical Research: Atmospheres, 115(D18):D18107, 2010.

[18] Fedor Mesinger, Geoff DiMego, Eugenia Kalnay, Kenneth Mitchell, Perry C Shafran, Wesley Ebisuzaki, Du $\AA_{j}$ an Jovic, Jack Woollen, Eric Rogers, Ernesto H Berbery, and others. North American regional reanalysis. Bulletin of the American Meteorological Society, 87(3):343-360, 2006.

[19] F.M. Monaldo, D.R. Thompson, W.G. Pichel, and P. Clemente-Colon. A systematic comparison of QuikSCAT and SAR ocean surface wind speeds. IEEE Transactions on Geoscience and Remote Sensing, 42(2):283-291, February 2004.

[20] N.G. Mortensen, L. Landberg, Ib Troen, and E. Lundtang Petersen. Wind atlas analysis and application program (WAsP). Technical Report Ris $\tilde{A}_{s}-\mathrm{I}-666(\mathrm{EN})(\mathrm{v} .1)$, Ris $\tilde{A}_{\text {s }}$ National Lab., Roskilde (Denmark). Meteorology and Wind Energy, 1993.

[21] National Ice Center. IMS Daily Northern Hemisphere Snow and Ice Analysis at 4 $\mathrm{km}$ and $24 \mathrm{~km}$ Resolution. 2008. Boulder, Colorado USA: National Snow and Ice Data Center. http://dx.doi.org/10.7265/N52R3PMC.

[22] Son V. Nghiem, George A. Leshkevich, and Bryan W. Stiles. Wind Fields over the Great Lakes Measured by the SeaWinds Scatterometer on the QuikSCAT Satellite. Journal of Great Lakes Research, 30(1):148-165, 2004.

[23] S Nghiem, G Leshkevich, and R Kwok. Great Lakes Ice Cover Classification and Mapping Using Satellite Synthetic Aperture Radar (SAR) Data. San Diego, California, 1998. Fifth International Conference on Remote Sensing for Marine and Coastal Environments.

[24] M. A. Oliver and R. Webster. Kriging: a method of interpolation for geographical information systems. International journal of geographical information systems, 4(3):313-332, July 1990. 
[25] D. L. Paton, A. Bass, D. G. Smith, D. L. Elliot, W. R. Barchet, and R. L. George. Wind Energy Resource Atlas: Volume 3-The Great Lakes Region. Technical Report PNL-3195, WERA-3, Pacific Northwest Laboratory, Richland, Washington, 1981.

[26] Mark H. Pickett, Wenqing Tang, Leslie K. Rosenfeld, and Carlyle H. Wash. QuikSCAT Satellite Comparisons with Nearshore Buoy Wind Data off the U.S. West Coast. Journal of Atmospheric and Oceanic Technology, 20(12):1869-1879, December 2003.

[27] S. C. Pryor and R. J. Barthelmie. 3.04 - Renewable Energy Resources â€“ Ocean Energy: Windâ€"Waveâ€"Tidalâ€"Sea Currents. In Roger A. Pielke, editor, Climate Vulnerability, pages 65-81. Academic Press, Oxford, 2013.

[28] S. C. Pryor, M. Nielsen, R. J. Barthelmie, and J. Mann. Can satellite sampling of offshore wind speeds realistically represent wind speed distributions? Part II: Quantifying uncertainties associated with distribution fitting methods. Journal of Applied Meteorology, 43(5):739-750, May 2004. WOS:000221825200008.

[29] Lucrezia Ricciardulli and Frank Wentz. Reprocessed QuikSCAT (V04) Wind Vectors with Ku-2011 Geophysical Model Function. Technical Report 043011, Remote Sensing Systems, Santa Rosa, California, 2011.

[30] Andrej Saulesleja. Great Lakes climatological atlas. Environment Canada, Atmospheric Environment Service, Ottawa, Canada, 1986.

[31] J. T. Schoof and S. C. Pryor. Assessing the fidelity of AOGCM-simulated relationships between large-scale modes of climate variability and wind speeds. Journal of Geophysical Research: Atmospheres, 119(16):2014JD021601, August 2014.

[32] Marc N Schwartz, Donna Heimiller, Steve Haymes, and Walt Musial. Assessment of offshore wind energy resources for the United States. Technical Report NREL/ TP - 500 - 45889, National Renewable Energy Laboratory, Golden, Colorado, 2010.

[33] Wenqing Tang, W.T. Liu, and B.W. Stiles. Evaluation of high-resolution ocean surface vector winds measured by QuikSCAT scatterometer in coastal regions. IEEE Transactions on Geoscience and Remote Sensing, 42(8):1762-1769, August 2004.

[34] Ib Troen and Erik Lundtang Petersen. European Wind Atlas. Commission of the 
European Communities, Directorate-General for Science, Research, and Development, Brussels, Belgium, 1989.

[35] Jia Wang, Xuezhi Bai, Haoguo Hu, Anne Clites, Marie Colton, and Brent Lofgren. Temporal and Spatial Variability of Great Lakes Ice Cover, 1973â€"2010*. Journal of Climate, 25(4):1318-1329, September 2011.

[36] Xiaofeng Yang, Xiaofeng Li, W.G. Pichel, and Ziwei Li. Comparison of Ocean Surface Winds From ENVISAT ASAR, MetOp ASCAT Scatterometer, Buoy Measurements, and NOGAPS Model. IEEE Transactions on Geoscience and Remote Sensing, 49(12):4743-4750, December 2011.

[37] Xiaofeng Yang, Xiaofeng Li, Quanan Zheng, XingFa Gu, W.G. Pichel, and Ziwei Li. Comparison of Ocean-Surface Winds Retrieved From QuikSCAT Scatterometer and Radarsat-1 SAR in Offshore Waters of the U.S. West Coast. IEEE Geoscience and Remote Sensing Letters, 8(1):163-167, January 2011.

[38] Igor Zahumensk $\tilde{A}^{1} \frac{1}{2}$. Guidelines on quality control procedures for data from automatic weather stations. Geneva, Switzerland, 2004. World Meteorological Organization.

\section{Figure Captions}

Figure 1: Great Lakes bathymetry shown as the shading (m), and location of the coastal stations and buoys used in the analysis. The color coding of the sites indicates the number of years of data considered in this work after quality control. The letters represent the initials of each Lake: Superior (S), Michigan (M), Huron (H), Georgian Bay (GB), Erie (E), Saint Clair (SC) and Ontario (O).

Figure 2: Schematic of the different data sources and the methodology applied to each one to generate wind speed maps and finally an observational wind atlas. For each data stream, the first line describes the number of sites (for coastal stations and buoys) or resolution (for satellites), the second line shows the temporal averaging period of the measurements (for coastal stations and buoys) or overpass frequency (for satellites). *For SAR, resolution of the derived wind maps is $500 \mathrm{~m}$ while original resolution of Envisat SAR Wide Swath Mode is $150 \mathrm{~m}$. The following lines represent the period of data availability, the data filtering criteria, and the processing steps. 
Figure 3: Number of coastal and buoy sites with complete data records, for each year from 2002 to 2012 for each of the Great Lakes.

Figure 4: Percent errors for the first moment of the Weibull distribution and for power density at $90 \mathrm{~m}$ when using NARR as a reference series and the method of ratios to correct for the seasonal bias artificially introduced in the data from coastal stations. The box plots are spatial averages across the coastal stations. For each coastal station, the number of years of data considered differs and is given in fig:sites.

Figure 5: Mean wind speed at $90 \mathrm{~m}$ as obtained from time series of 90 coastal stations and buoys from 2002 to 2012 and after correcting for the lack of ice-season data in the buoy records, processing with WAsP, merging and kriging. Overlaid circles illustrate mean biases in the final resource map where single (double) line represents an under (over) estimation of the resource (in $m s^{-1}$ ), in comparison with the wind speed predicted by WAsP at the buoy locations after ice correction.

Figure 6: Spatial distribution of the availability of SAR wind speed estimates for each over water pixel (shading) from 2002 to 2012 and the location of the measurement sites used to generate the weights for the wind class method (markers).

Figure 7: Wind class roses for the Great Lakes. Horizon is divided into 1230 sectors, which are then divided into 4 wind speed classes given by the bar radii. Radii contours are at 5, 10, 15, and 20 $m s^{-1}$. Colors represent the weight $(\%)$ of each class.

Figure 8: Example of two wind classes for Lake Erie: (a) $\theta=0 \pm 15,5 \leq|\vec{u}|<10 \mathrm{~ms}^{-1}$, weight $=2.06 \%$ and (b) $175 \leq \theta<195,4 \leq|\vec{u}|<7 \mathrm{~ms}^{-1}$, weight $=4.73 \%$. Shading represents equivalent neutral wind speed at $10 \mathrm{~m}\left(\mathrm{~ms}^{-1}\right)$. 
Figure 9: Mean wind speed at $90 \mathrm{~m}$ as obtained from SAR winds from 2002 to 2012 using the wind class method. Overlaid circles illustrate mean biases in the final resource map where single (double) line represents an under (over) estimation of the resource (in $m s^{-1}$ ), in comparison with the wind speed predicted by WAsP at the buoy locations after ice correction.

Figure 10: Spatial distribution of the availability of QuikSCAT wind speed estimates for each over water pixel (shading) from 1999 to 2009.

Figure 11: Mean wind speed at $90 \mathrm{~m}$ as obtained from QuikSCAT equivalent neutral winds from 1999 to 2009 and corrected for lack of ice-season data. Overlaid circles illustrate mean biases in the final resource map where single (double) line represents an under (over) estimation of the resource (in $m s^{-1}$ ), in comparison with the wind speed predicted by WAsP at the buoy locations after ice correction.

Figure 12: Observationally-derived wind atlas for the Great Lakes as obtained from QuikSCAT, SAR, coastal stations and buoys. Wind atlas is described both in terms of mean wind speed $\left(\mathrm{ms}^{-1}\right)$ and mean energy density $\left(0.5 \rho u^{3} \mathrm{Wm}^{-2}\right)$ at five heights $(10,25,50,90,150 \mathrm{~m})$. The mean energy density was calculated assuming the given wind speed as constant. Note that nine-point local smoothing was applied to the plot. The classes and coloring conventions used are as in the European Wind Atlas [34]. 
Fig. 1

Site Locations and Great Lakes Bathymetry (m)

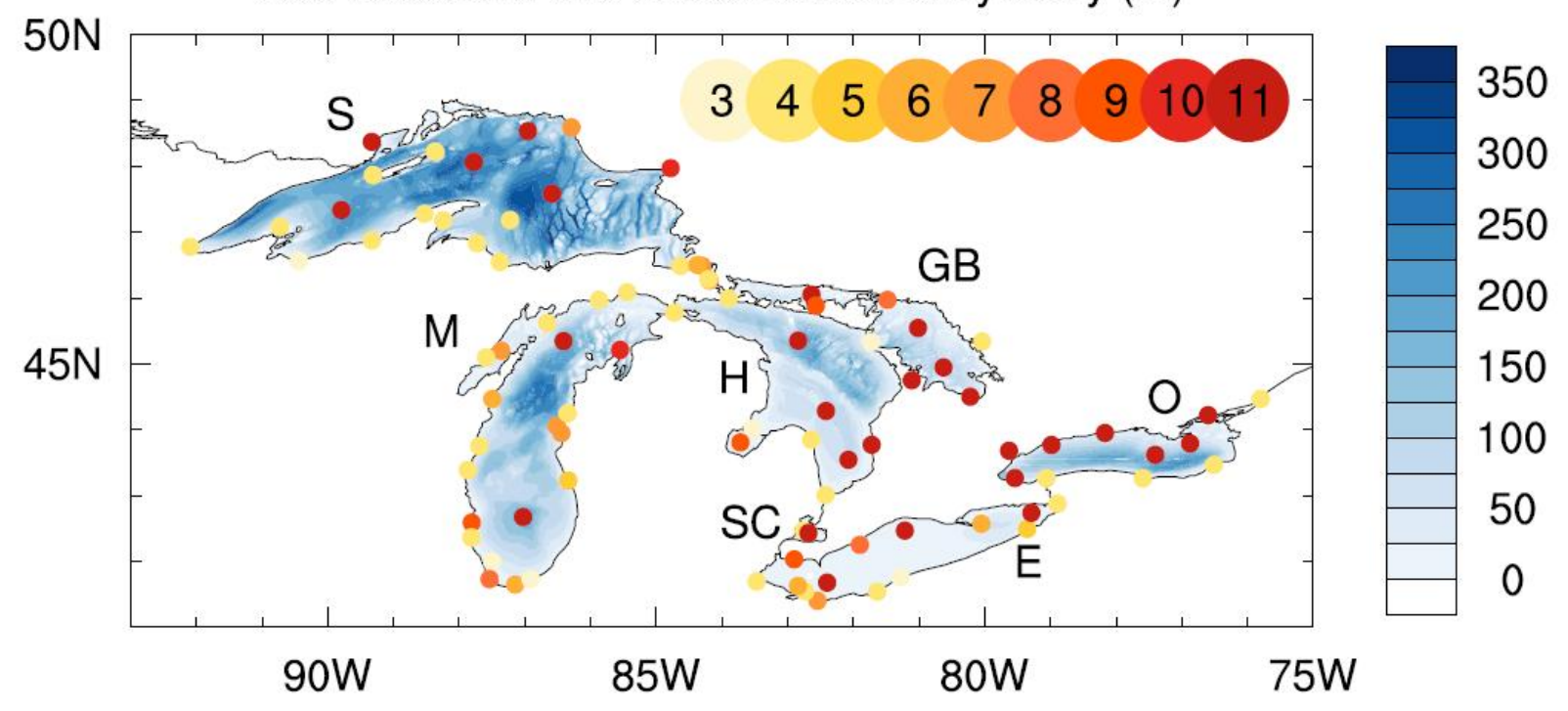


Fig. 2

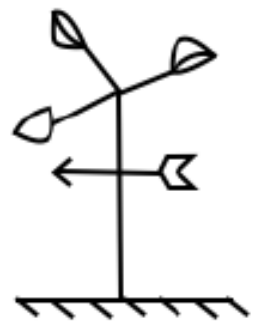

Stations

70 sites

$\mathrm{z} \sim 6 \mathrm{~m}-47 \mathrm{~m}$

6 min to 1 hour 2002 - 2012

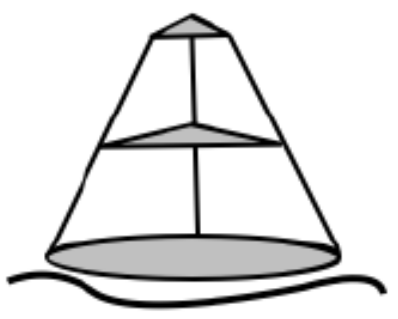

Buoys

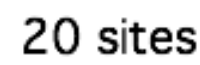

$z \sim 3 \mathrm{~m}-5 \mathrm{~m}$

10 min to 1 hour 2002 - 2012

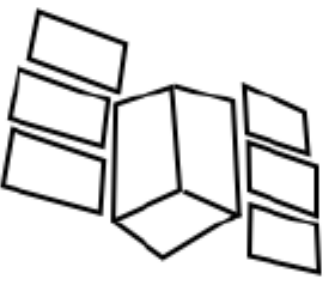

QuikSCAT

25-km grid cells $\mathrm{z}=10 \mathrm{~m}$

$2 x$ daily 1999 - 2009

2.0 to $25.0 \mathrm{~ms}^{-1} \&$ ice mask

0.4 to $75.0 \mathrm{~ms}^{-1} \& 70 \%$ availability

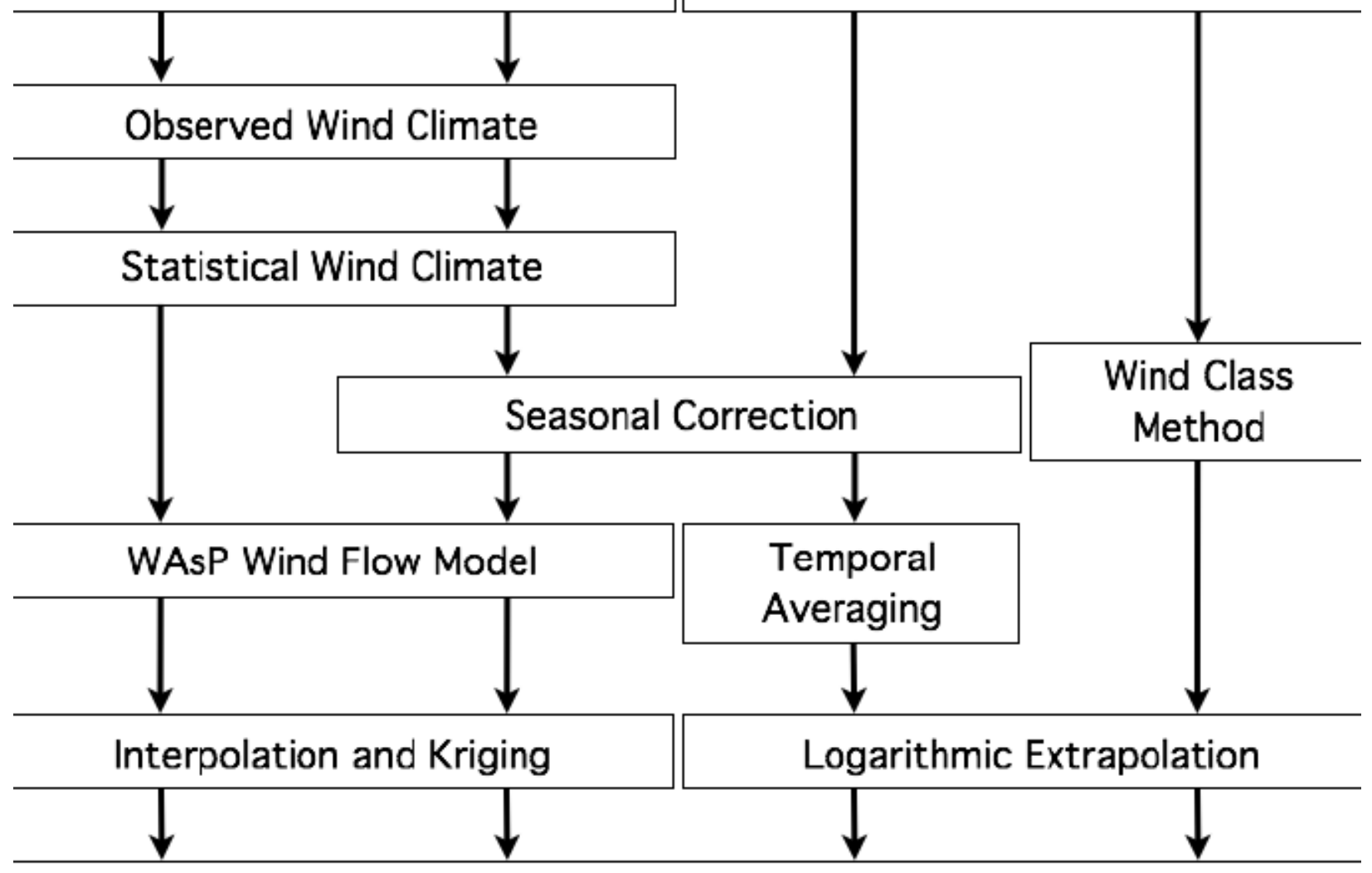

Offshore Mean Wind Maps 
Fig. 3

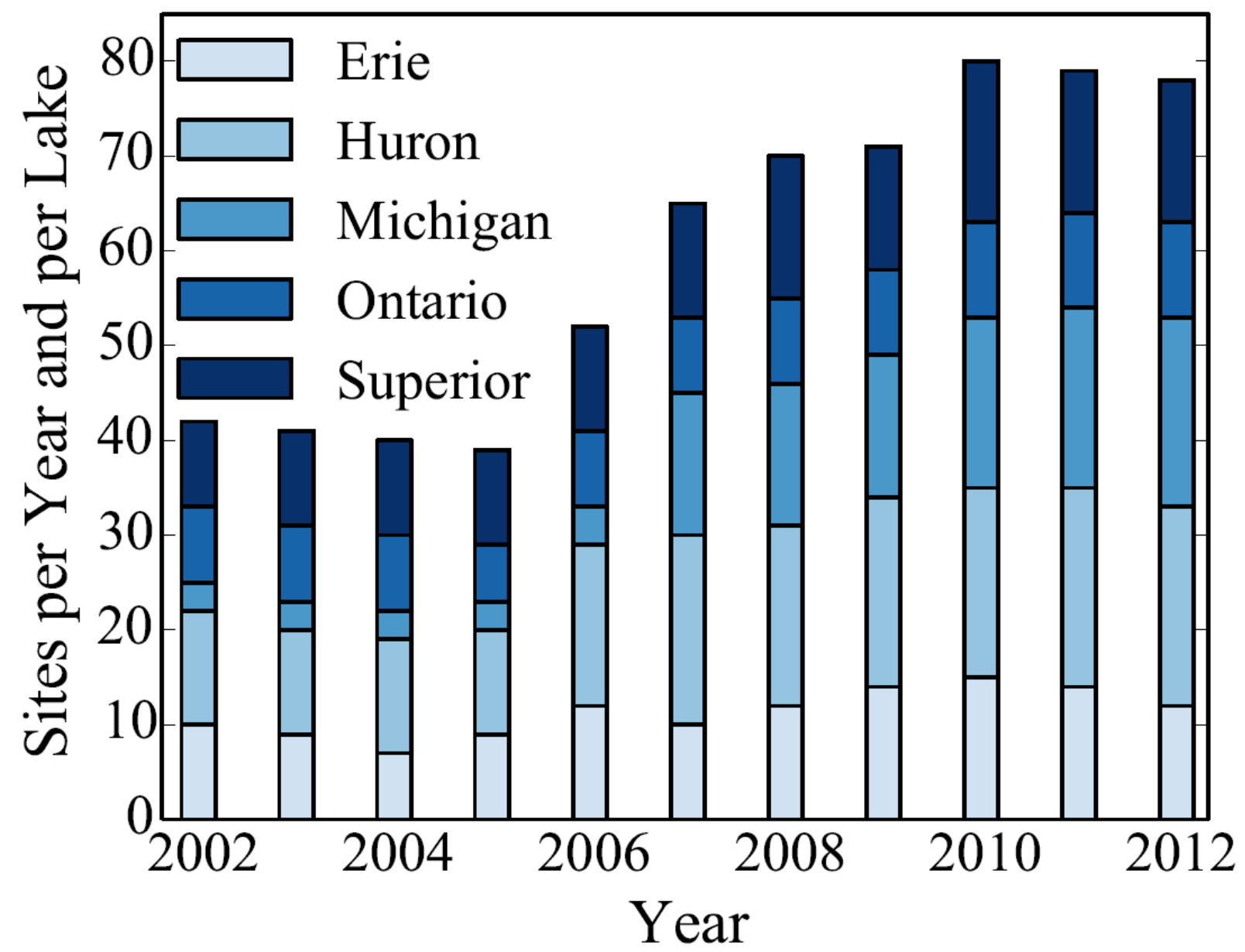


Fig. 4

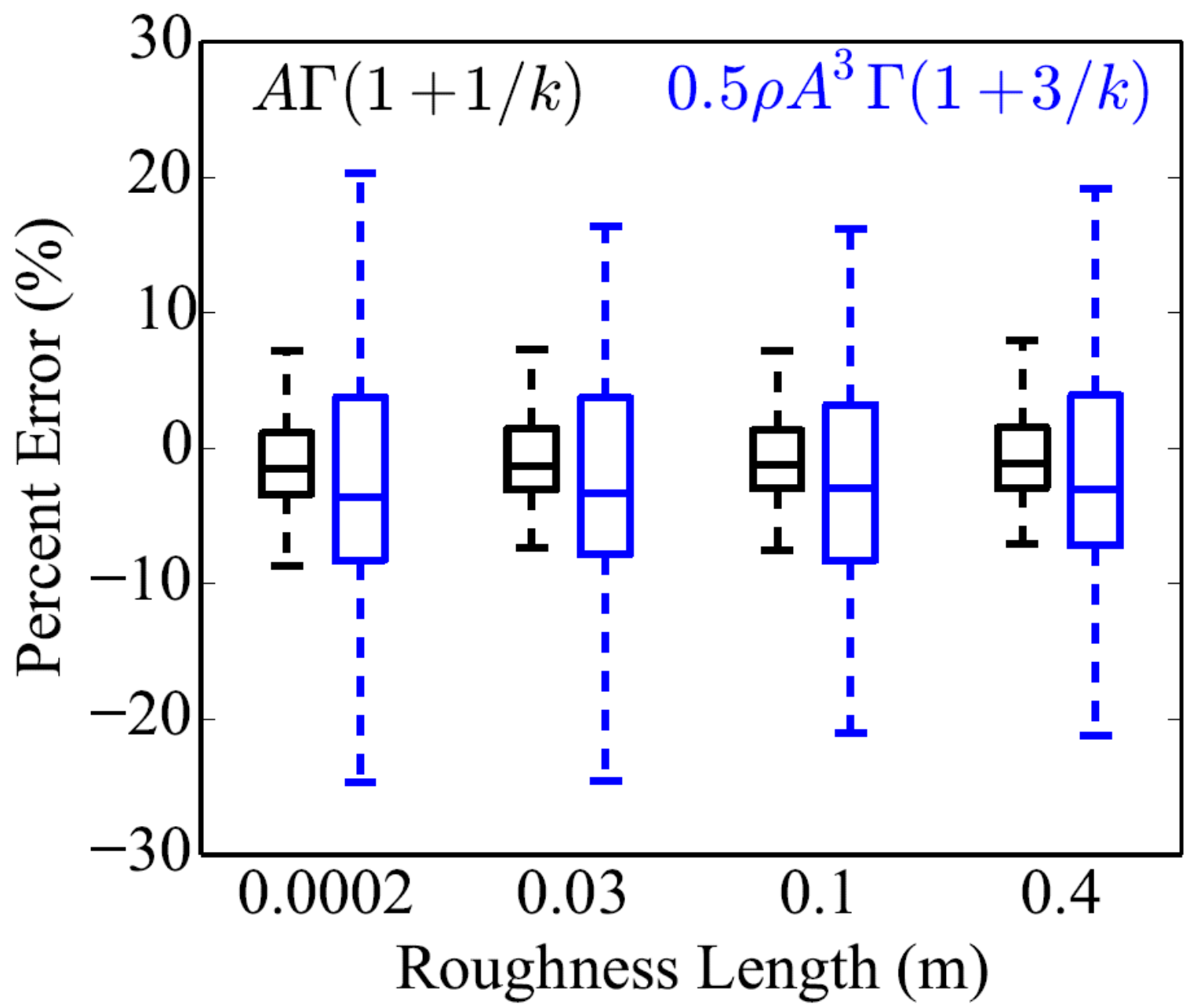


Fig. 5

Sites and Buoys: Mean Wind Resource at $90 \mathrm{~m}$

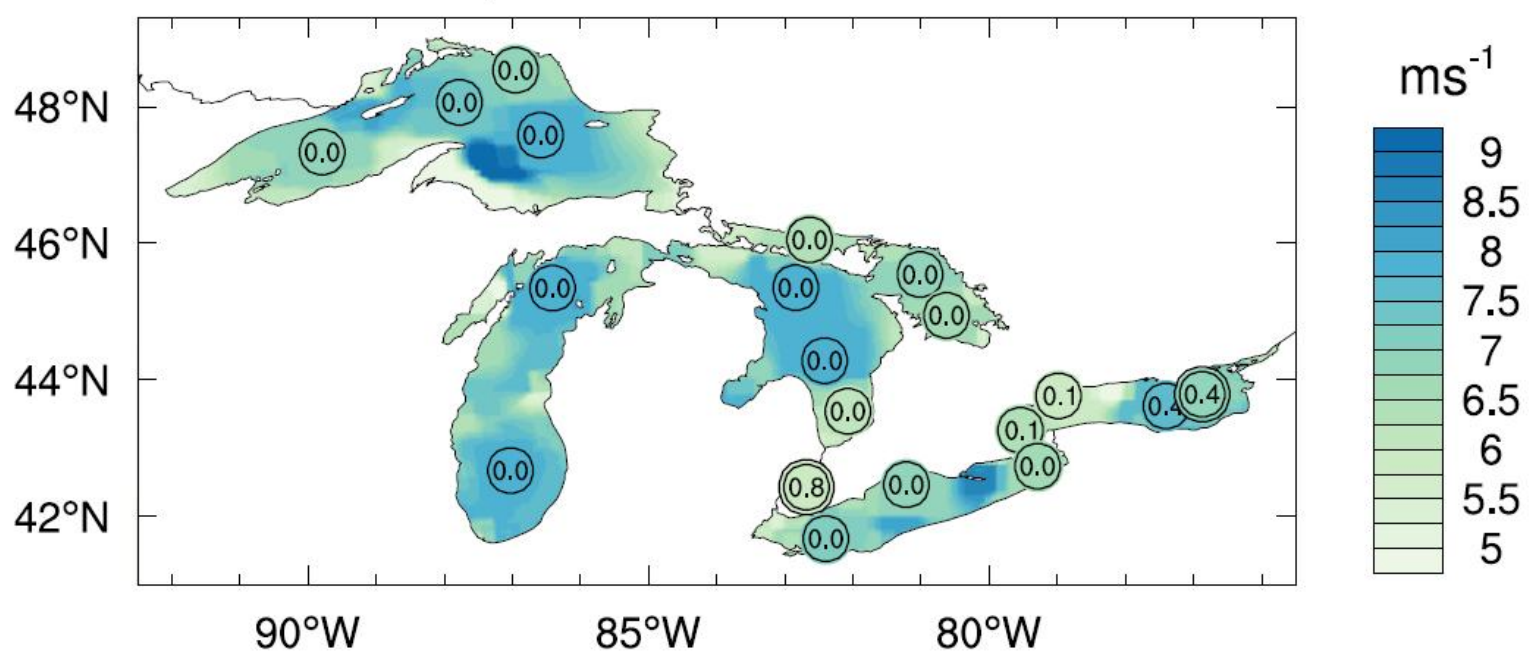


Fig. 6

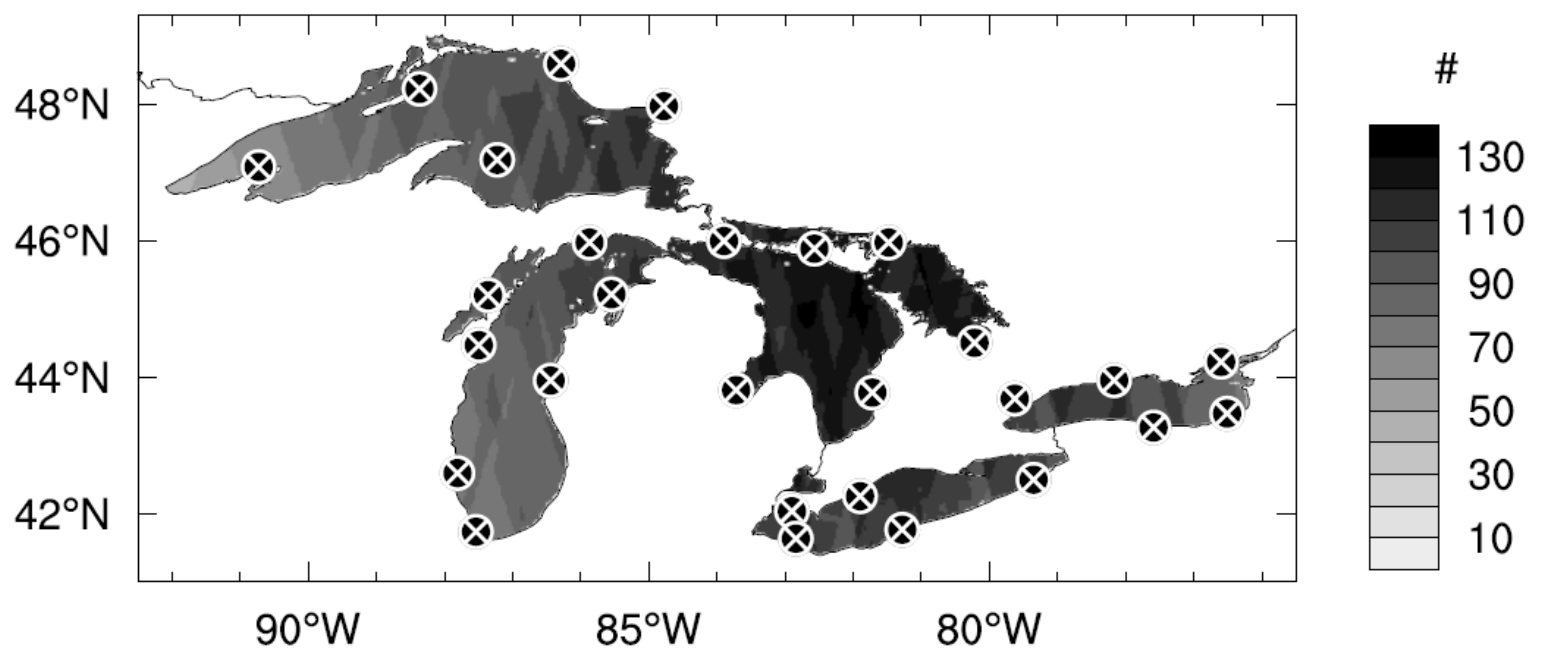


Fig. 7

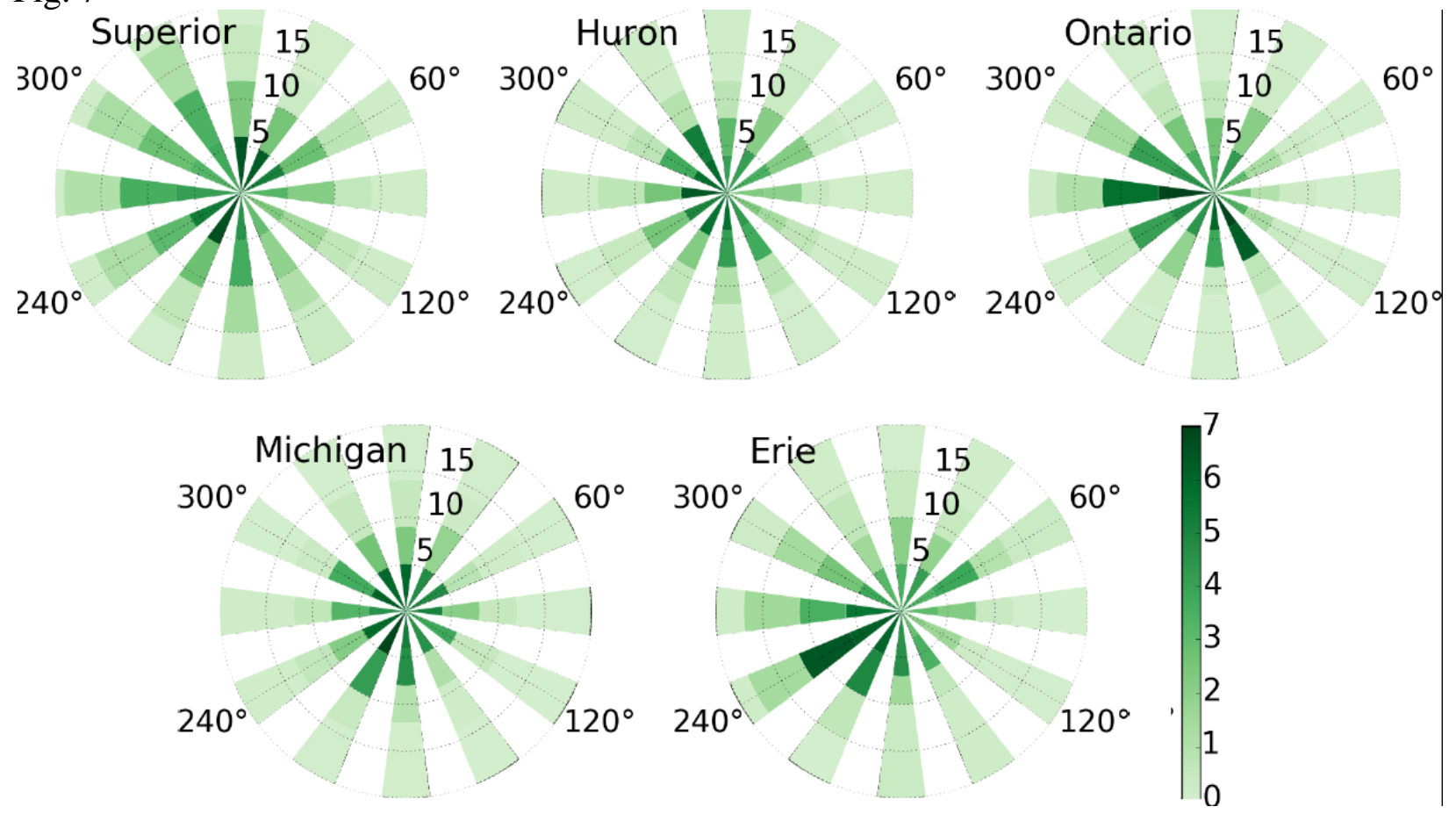


Fig. 8

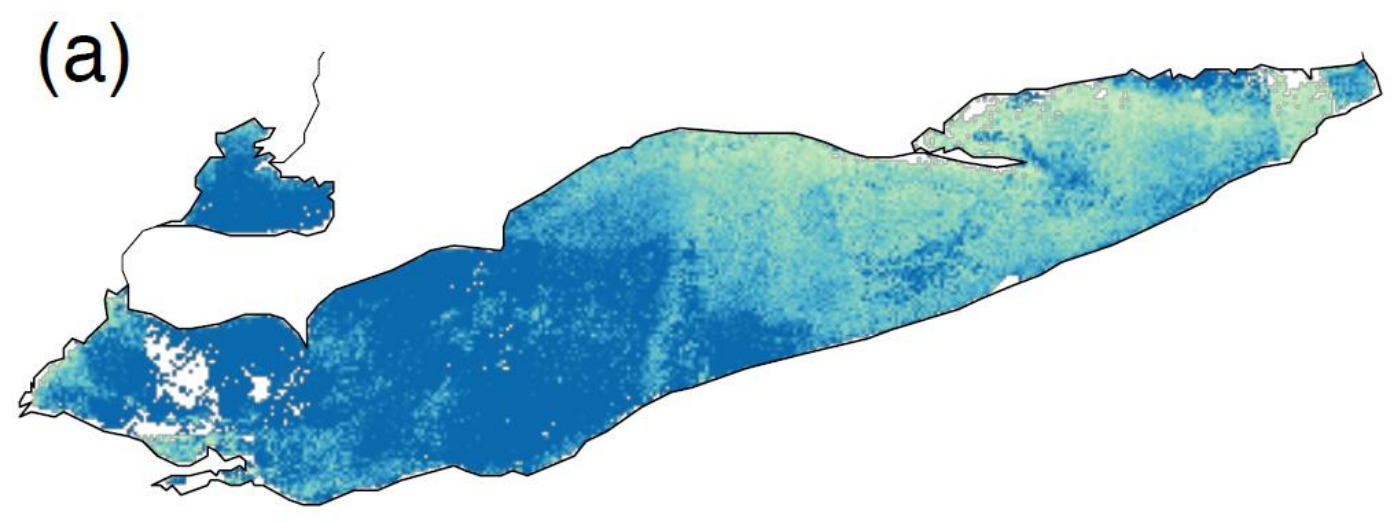

(b)
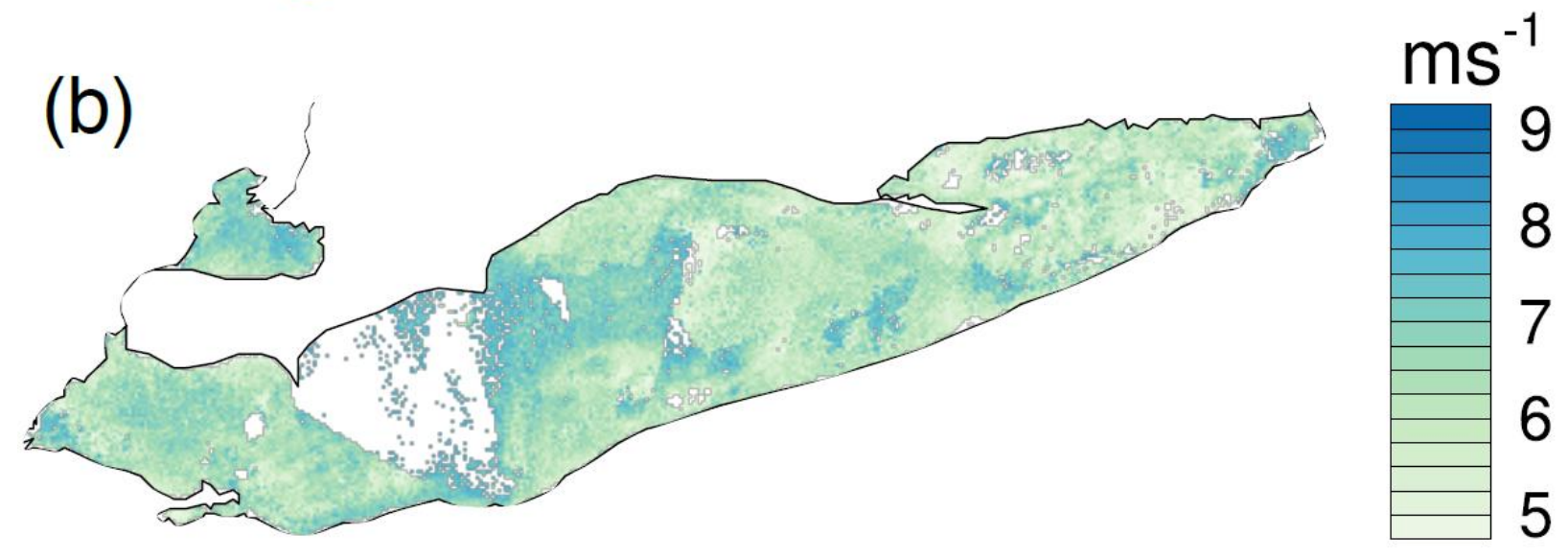
Fig. 9

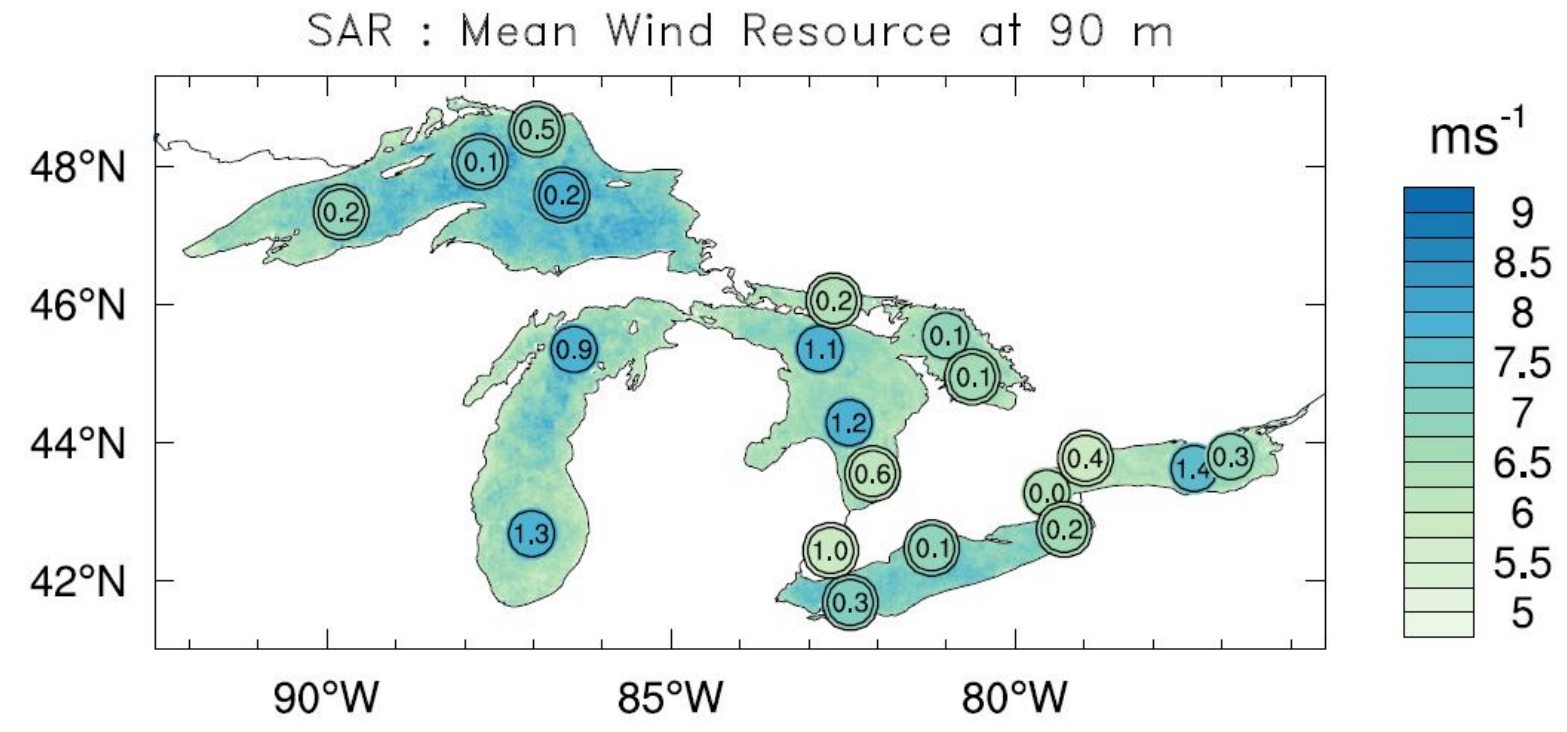


Fig. 10

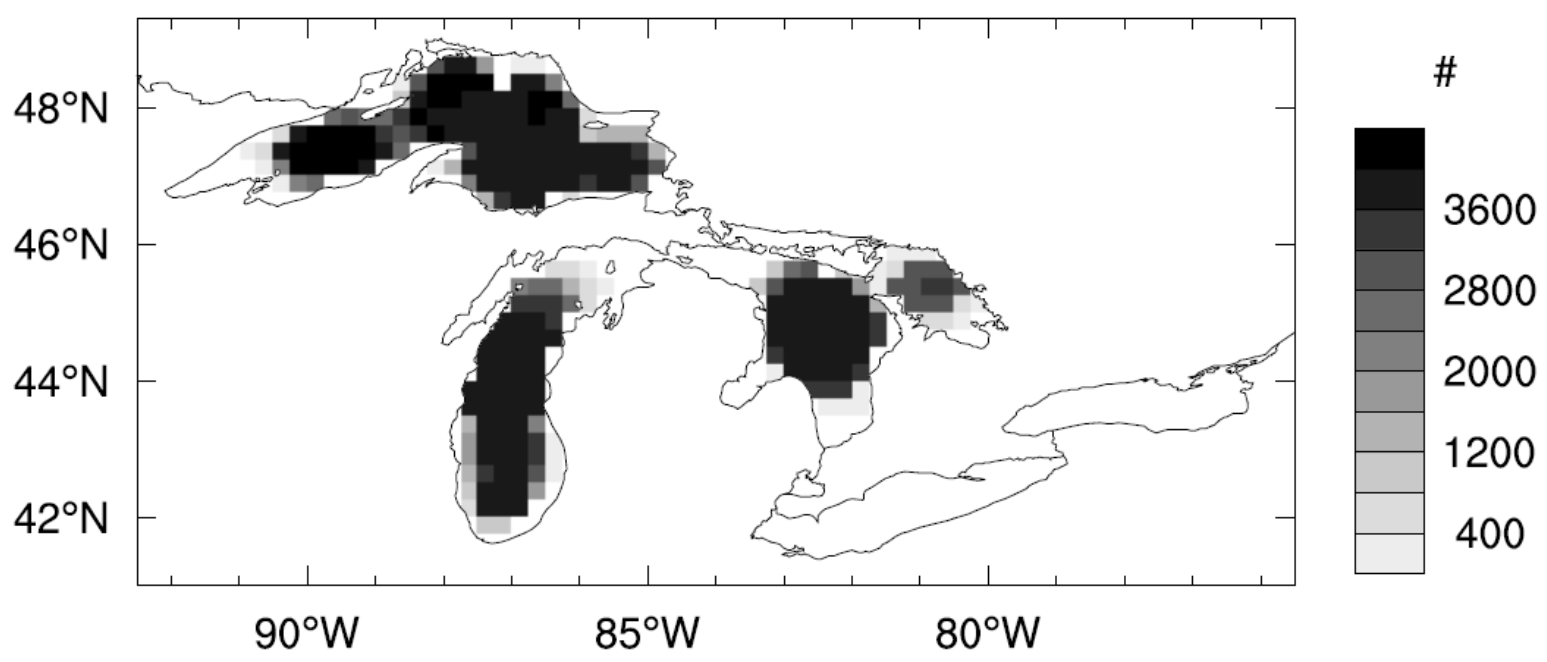


Fig. 11

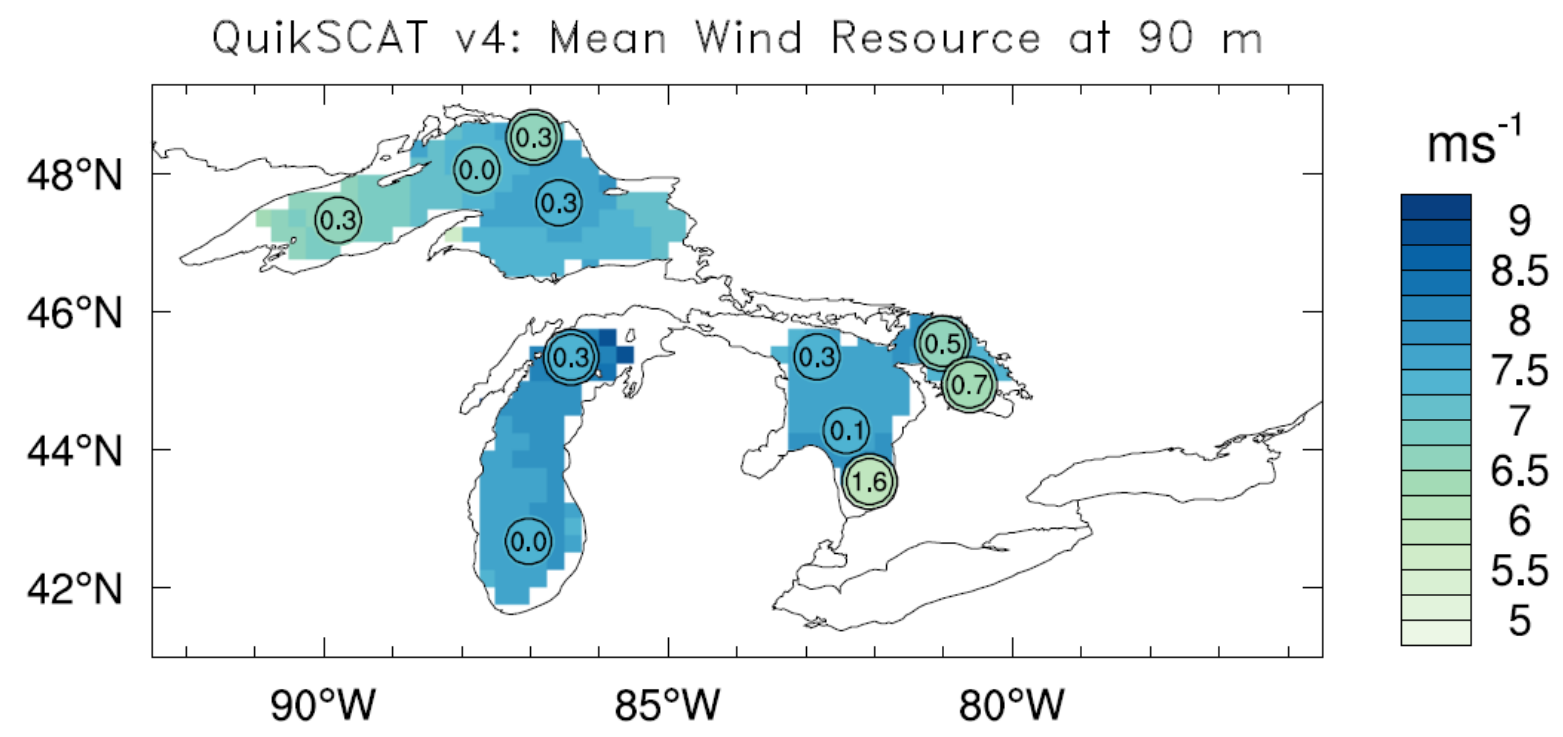


Fig. 12

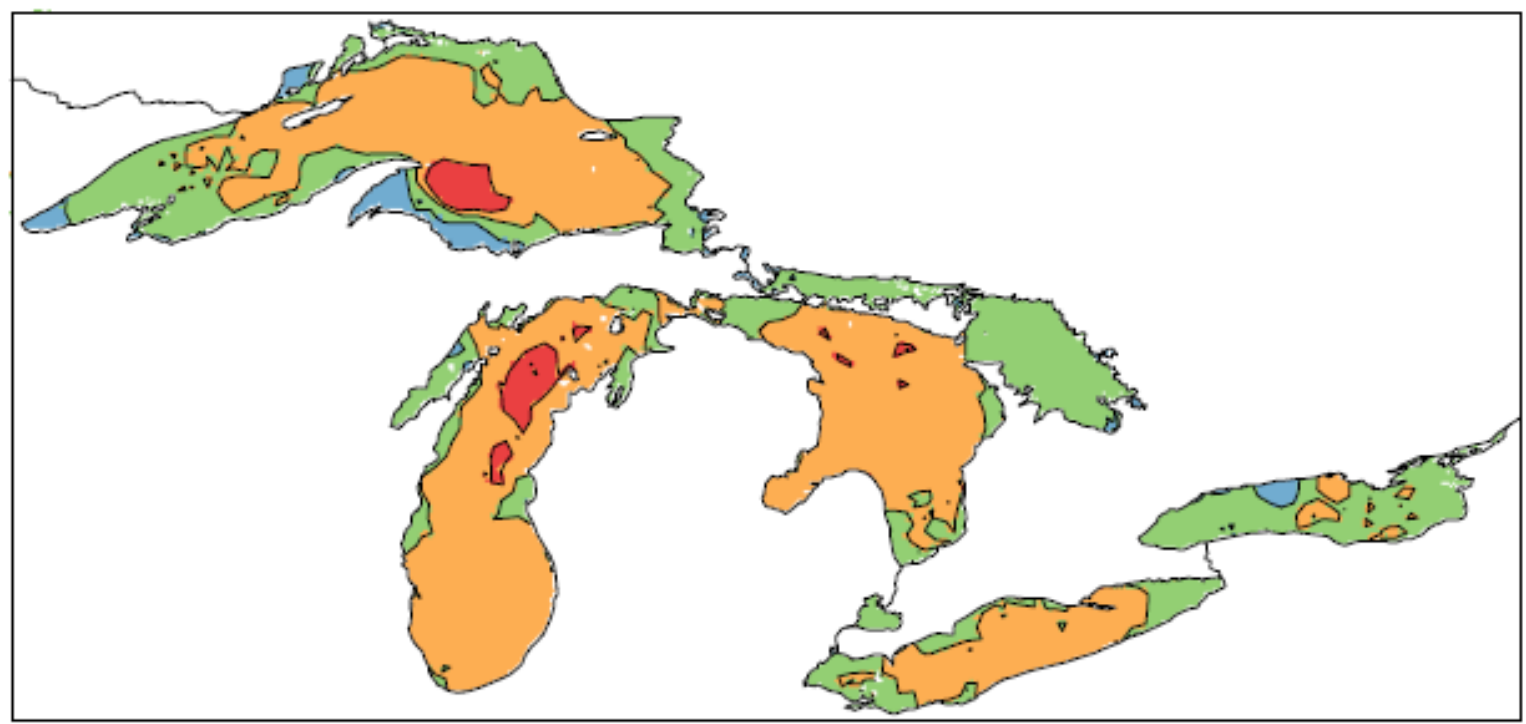

\begin{tabular}{|c|c|c|c|c|c|c|c|c|c|}
\hline & $n$ & & $\mathrm{~m}$ & & m & & $\mathrm{m}$ & & $n$ \\
\hline $\mathrm{ms}$ & $\mathrm{Wm}^{-2}$ & $\mathrm{~ms}^{-1}$ & $\mathrm{Wm}^{-2}$ & $\mathrm{~ms}^{-1}$ & $\mathrm{Wm}^{-2}$ & $\mathrm{~ms}^{-1}$ & $\mathrm{Wm}^{-2}$ & $\mathrm{~ms}^{-}$ & $\mathrm{Wm}^{-2}$ \\
\hline$<7.5$ & $<258$ & $<8.1$ & $<326$ & $<8.6$ & $<390$ & $<9.0$ & $<447$ & $<9.4$ & $<509$ \\
\hline$<6.6$ & $<176$ & $<7.2$ & $<229$ & $<7.6$ & $<269$ & $<8.0$ & $<314$ & $<8.3$ & $<350$ \\
\hline$<5.8$ & $<120$ & $<6.3$ & $<153$ & $<6.7$ & $<184$ & $<7.0$ & $<210$ & $<7.3$ & $<238$ \\
\hline$<5.0$ & $<077$ & $<5.4$ & $<096$ & $<5.7$ & $<113$ & $<6.0$ & $<132$ & $<6.2$ & $<146$ \\
\hline
\end{tabular}

